ARTICLE

DOI: $10.1038 / s 41467-018-07358-9$

\title{
Downregulation of macrophage Irs2 by hyperinsulinemia impairs IL-4-indeuced M2a- subtype macrophage activation in obesity
}

\author{
Tetsuya Kubota1,2,3,4,5, Mariko Inoue ${ }^{1,3}$, Naoto Kubota1,2,3,6, Iseki Takamoto1, \\ Tomoka Mineyama ${ }^{1}$, Kaito Iwayama ${ }^{7}$, Kumpei Tokuyama7, Masao Moroi ${ }^{4}$, Kohjiro Ueki ${ }^{1}$, \\ Toshimasa Yamauchi id ${ }^{1}$ \& Takashi Kadowaki (i) 1,8,9
}

M2a-subtype macrophage activation is known to be impaired in obesity, although the underlying mechanisms remain poorly understood. Herein, we demonstrate that, the IL-4/ Irs2/Akt pathway is selectively impaired, along with decreased macrophage Irs2 expression, although IL-4/STAT6 pathway is maintained. Indeed, myeloid cell-specific Irs2-deficient mice show impairment of IL-4-induced M2a-subtype macrophage activation, as a result of stabilization of the FoxO1/HDAC3/NCoR1 corepressor complex, resulting in insulin resistance under the HF diet condition. Moreover, the reduction of macrophage Irs2 expression is mediated by hyperinsulinemia via the insulin receptor (IR). In myeloid cell-specific IR-deficient mice, the IL-4/Irs2 pathway is preserved in the macrophages, which results in a reduced degree of insulin resistance, because of the lack of IR-mediated downregulation of Irs2. We conclude that downregulation of Irs2 in macrophages caused by hyperinsulinemia is responsible for systemic insulin resistance via impairment of M2a-subtype macrophage activation in obesity.

\footnotetext{
${ }^{1}$ Department of Diabetes and Metabolic Diseases, Graduate School of Medicine, The University of Tokyo, Tokyo $113-8655$, Japan. ${ }^{2}$ Laboratory for Intestinal Ecosystem, RIKEN Center for Integrative Medical Sciences (IMS), Kanagawa 230-0045, Japan. ${ }^{3}$ Department of Clinical Nutrition, National Institute of Health and Nutrition, Tokyo 162-8636, Japan. ${ }^{4}$ Division of Cardiovascular Medicine, Toho University Ohashi Medical Center, Tokyo 153-8515, Japan. ${ }^{5}$ Analysis tool development group, Intestinal microbiota project, Kanagawa Institute of Industrial Science and Technology, Kanagawa 213-0012, Japan. ${ }^{6}$ Department of Clinical Nutrition Therapy, University of Tokyo, Tokyo 113-8655, Japan. ${ }^{7}$ Graduate School of Comprehensive Human Sciences, University of Tsukuba, Tsukuba 305-8577, Japan. ${ }^{8}$ Department of Prevention of Diabetes and Lifestyle-Related Diseases, Graduate School of Medicine, The University of Tokyo, Tokyo, Japan. ${ }^{9}$ Department of Metabolism and Nutrition, Mizonokuchi Hospital, Faculty of Medicine, Teikyo University, Tokyo, Japan. These authors contributed equally: Tetsuya Kubota, Mariko Inoue, Naoto Kubota. Correspondence and requests for materials should be addressed to N.K. (email: nkubota-tky@umin.ac.jp) or to T.K. (email: kadowaki-3im@h.u-tokyo.ac.jp)
} 
O besity is known to cause chronic low-grade inflammation, resulting in insulin resistance and type 2 diabetes ${ }^{1,2}$. Chronic low-grade inflammation is recognized as being caused by adipose tissue macrophage (ATM) accumulation, which has been shown to increase with body weight gain in both humans and rodents ${ }^{3-8}$. Thus, macrophages (MФs) per se are, at least in part, responsible for the insulin resistance observed in obesity. МФs can be divided into two major populations; the M1type $M \Phi s$, representing the classically activated $M \Phi s$, which are activated by Th1 cytokines to generate proinflammatory cytokines, and the M2-type MФs, representing the alternatively activated $M \Phi$ s, which are activated by Th2 cytokines to generate anti-inflammatory cytokines ${ }^{9}$. ATMs from lean mice showed high expression levels of the M2-type MФ marker genes. These expressions were found to be decreased under the high-fat (HF) diet condition ${ }^{10}$, associated with aggravation of the insulin resistance $^{11,12}$. M2-type MФs are classified at least in three subpopulations, M2a-subtype, M2b-subtype and M2c-subtype, based upon the inducing agent and molecular marker expression. M2asubtype MФs activated by IL-4 or IL-13 promote of Th2-type inflammation against enhanced fibrosis and wound healing by increased arginase1(Arg1), FIZZ1 (also called Retnla) and Ym1 (also called Chi3l3) expression levels. M2b-subtype MФs are induced by combined exposure to immune complexes with Tolllike receptor (TLR)- or IL-1 receptor (IL1R)-ligands, whereas M2c-subtype MФs are induced by IL-10. M2b-subtype MФs with concomitant high IL-10 and low IL-12 suppress inflammatory cytokines and molecules involving in lymphocytic activation. M2c-subtype MФs are thought to be predominantly responsible for negative/deactivating immunoregulation ${ }^{13,14}$.

In the adipose tissue, eosinophils are recognized as a source of IL-4 production, and eosinophil-deficient mice showed insulin resistance and impaired glucose tolerance under the $\mathrm{HF}$ diet condition, with a decrease of IL-4 production and number of M2a-subtype $M \Phi s^{15}$. Decreased M2a-subtype $M \Phi$ activation by IL-4 renders mice susceptible to diet-induced obesity and glucose intolerance $^{16}$. These data suggest that $M 2$ a-subtype $M \Phi$ activation by IL- 4 is impaired in obesity, resulting in obesity-induced insulin resistance.

IL-4 binds to two types of receptors; the type I receptor, which is composed of IL-4 receptor (IL-4R) $\alpha$ and the common $\gamma$ chain $(\gamma \mathrm{C})$, and the type II receptor, which is composed of IL-4R $\alpha$ and IL-13 receptor (IL-13R) $\alpha 1^{17}$. IL-4R $\alpha$ binds janus kinases (JAK) 1 , which is crucial for the phosphorylation of signal transducer and activator of transcription 6 (STAT6). IL-4-induced STAT6 phosphorylation was necessary for M2a-subtype $\mathrm{M} \Phi$ activation. In fact, M2a-subtype $M \Phi$ activation by IL- 4 was impaired in systemic STAT6-deficient mice and myeloid cell-specific $I L-4 R \alpha$ deficient mice ${ }^{16,18,19}$. In addition to STAT6, Irs2, which was previously called IL-4-induced phosphotyrosine (4PS) ${ }^{20}$, is also activated and phosphorylated by IL- 4 via the $\gamma_{\mathrm{C}}$ in macrophages. IL-4-induced Irs2 phosphorylation and M2a-subtype macrophage activation were decreased in $\gamma_{C}$-deficient macrophages ${ }^{21}$. However, the underlying mechanisms by which M2a-subtype macrophage activation by IL-4 was impaired in obesity remain poorly understood. To clarify whether Irs2 is involved in impaired IL-4induced M2a-subtype macrophage activation, we analyzed myeloid cell-specific Irs2-deficient (MIrs2KO) mice under the high-fat (HF) diet condition, and attempted to determine the signaling mechanisms by which IL-4/Irs2 pathway would regulate M2asubtype macrophage activation.

\section{Results}

MIrs2KO mice exhibited insulin resistance and inflammation. To investigate the IL-4 signaling in MФs in obesity, peritoneal
MФs were collected from normal chow (NC) and HF diet-fed mice after thioglycollate injection. The phosphorylation levels of STAT6 induced by IL- 4 in the peritoneal MФs did not differ between the NC and HF diet-fed mice (Fig. 1a). In contrast, the phosphorylation levels of Irs2 induced by IL-4 were significantly reduced along with decreased MФ Irs 2 expression in the HF dietfed mice (Fig. 1a and Supplementary Fig. 1a). SiglecF ${ }^{-}$CD11 $b^{+}$F4/ $80^{+}$cells of the stromal vascular fraction (SVF) of the white adipose tissue (WAT) were collected from mice with genetically (ob/ob) or environmentally induced (15-week, HF diet-fed) obesity (Supplementary Fig. 1b). While there were no significant differences in the expression levels of $I R, I L-4 R$ or STAT6 between the two mouse models of obesity (Supplementary Fig. 1b, c), the expression levels of Irs 2 mRNA were significantly reduced in both (Fig. 1b, c). Expression of Irs1 mRNA was undetectable in these cells, as previously reported (Supplementary Fig. 1c, d) ${ }^{22}$. Since it has been shown that the M1- and M2-type MФ fractions are clearly separable using CD11c and CD206, the classic markers of M1- and M2-type MФs, respectively ${ }^{23}$, we investigated the expression levels of Irs 2 in siglecF ${ }^{-} \mathrm{CD} 11 \mathrm{~b}^{+} \mathrm{F} 4 / 80^{+} \mathrm{CD} 1 \mathrm{c}^{+}$cells (M1-type MФs) and siglecF ${ }^{-} \mathrm{CD} 11 \mathrm{~b}^{+} \mathrm{F} 4 / 80^{+} \mathrm{CD} 206^{+}$cells (M2type MФs) in the SVCs of the adipose tissue derived from NC and HF diet-fed mice. The expression levels of Irs 2 mRNA were significantly reduced in both the types of cells derived from HF dietfed mice (Supplementary Fig. 1e). These data suggest that IL-4/ Irs2-mediated signaling in the MФs is impaired in obesity.

To investigate the role of Irs2 in the MФs, we then generated MIrs2KO mice. Although there were no significant differences in the mRNA expression levels of $I R$ or $I L-4 R$ in the bone marrowderived MФs (BMDM) between the control and MIrs2KO mice, the Irs 2 mRNA and protein expressions were almost completely abrogated in the BMDM of the MIrs2KO mice (Supplementary Fig. 2a, b). Furthermore, Irs1 mRNA expression was undetectable in the BMDM of both the control and MIrs2KO mice (Supplementary Fig. 2a). There were no significant differences in the body weight (BW), results of the insulin tolerance test (ITT) and oral glucose tolerance test (OGTT) or the lipid profiles between the two models of mice under the NC diet condition (Supplementary Fig. 2c-f). We analyzed the percentages of the siglecF ${ }^{-} \mathrm{CD} 11 \mathrm{~b}^{+} \mathrm{F} 4 / 80^{+}$cells, siglecF ${ }^{-} \mathrm{CD} 11 \mathrm{~b}^{+} \mathrm{F} 4 / 80^{+} \mathrm{CD} 11 \mathrm{c}^{+}$ cells and siglecF-CD11b ${ }^{+} \mathrm{F} 4 / 80^{+} \mathrm{CD} 206^{+}$cells in the SVF of the adipose tissue derived from the NC-fed MIrs $2 \mathrm{KO}$ mice. There were no differences in the percentages of any of these cells between the control and MIrs2KO mice under the NC diet condition (Supplementary Fig. 2g). Under HF diet condition, however, the blood glucose and plasma insulin levels during the OGTT were significantly higher in the MIrs2KO mice, although there were no significant differences in the BW gain, lean body mass or percent body fat (\%FAT) between the control and MIrs2KO mice (Fig. 1d and Supplementary Fig. 3a, b). In the hyperinsulinemic-euglycemic clamp study, the MIrs2KO mice showed a reduced glucose infusion rate (GIR) and increased endogenous glucose production (EGP) (Fig. 1e). The phosphorylation levels of Akt in the liver and WAT, but not in the skeletal muscle, were significantly decreased in the MIrs2KO mice after insulin infusion via the vena cava (Fig. 1f). These data suggest that the lack of Irs2 in the MФs causes hepatic and WAT insulin resistance under the HF diet condition. In fact, the blood glucose levels during the pyruvate tolerance test (PTT) and expression levels of phosphoenolpyruvate carboxykinase (PEPCK) and glucose 6-phosphatase (G6Pase) in the liver were significantly increased in the HF diet-fed MIrs2KO mice (Supplementary Fig. 3c, d). Moreover, the hepatic triglyceride (TG) content was significantly increased in the HF diet-fed MIrs2KO mice (Supplementary Fig. 3e). There were no significant differences in the expression levels of sterol regulatory element binding protein $(S R E B P 1) c$, 
a
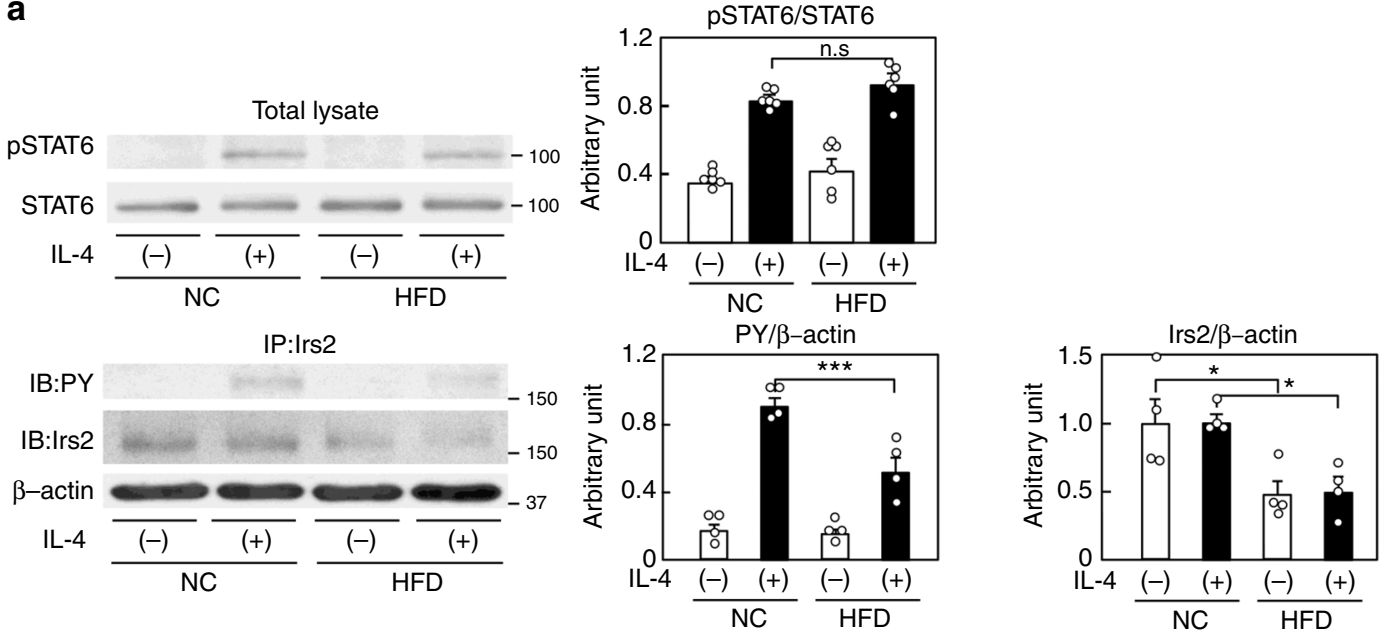

b

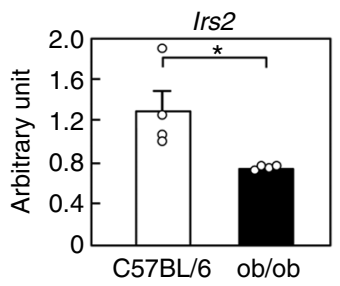

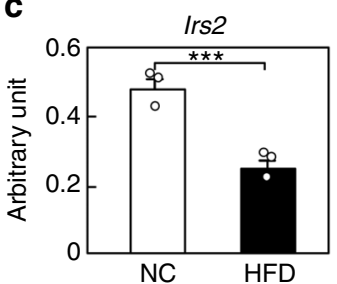

d

Oral glucose tolerance test

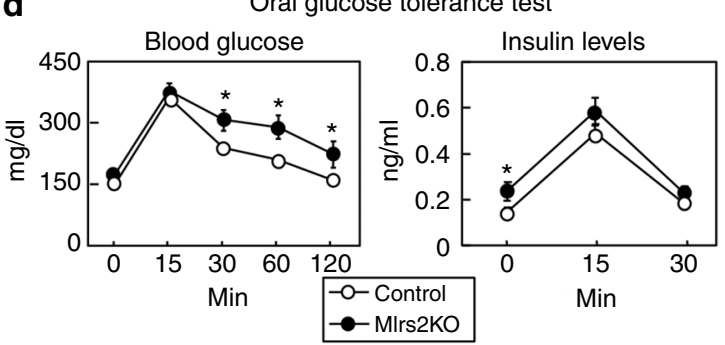

e
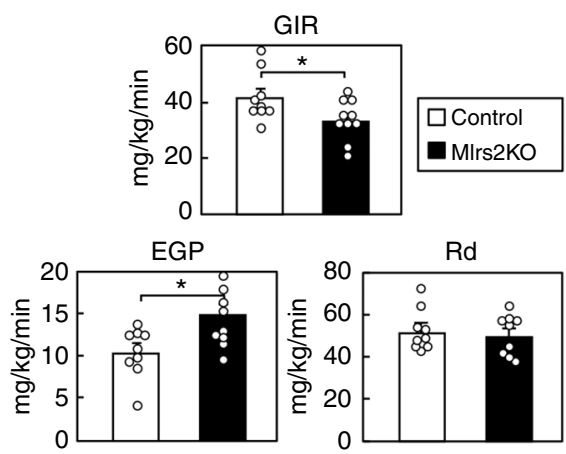

g

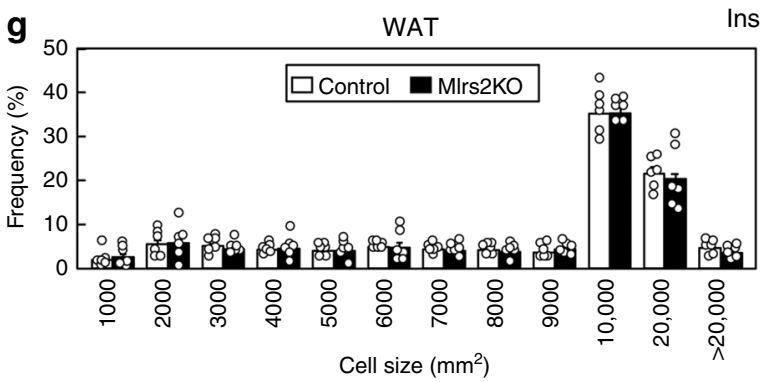

h

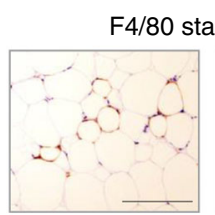

Control

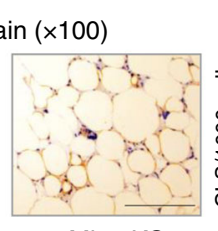

MIrs2KO

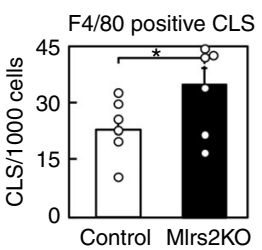

f
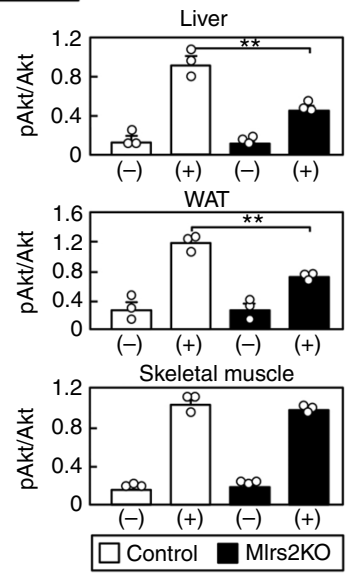

i
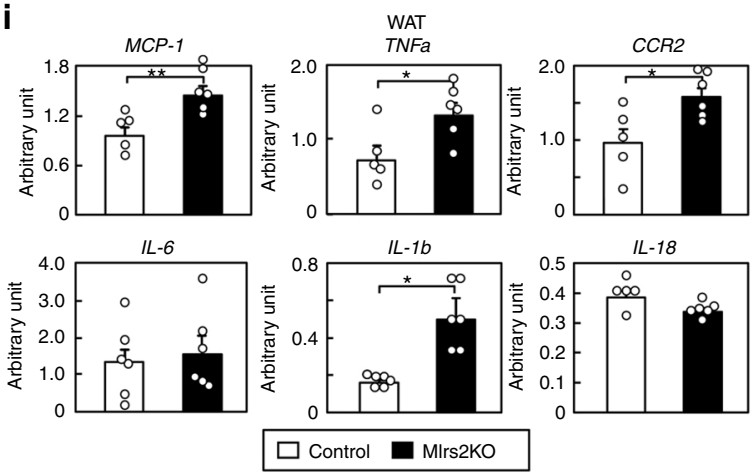

Fig. 1 M $\Phi$ Irs2 deficiency caused inflammation and insulin resistance in the liver and WAT under a HF diet. a Phosphorylation and protein levels of STAT6

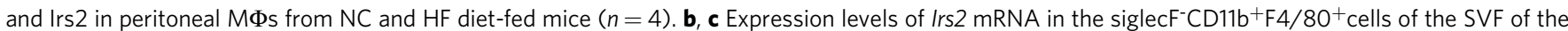
adipose tissue from ob/ob and HF diet-fed mice $(n=4)$. $\mathbf{d}$ Glucose tolerance test in the M/rs2KO mice $(n=7-14)$. e GIR, EGP and Rd in the M/rs2KO mice in the hyperinsulinemic-euglycemic clamp study $(n=9-10)$. f Phosphorylation levels of Akt (ser473) in the liver, WAT and skeletal muscle of the M/rs2KO mice after insulin infusion $(n=3-4)$. $\mathbf{g}$ Adipocyte cell size in the M/rs2KO mice $(n=6)$. $\mathbf{h}$ F4/80-positive CLS in the WAT of M/rs2KO mice (scale bar, $200 \mu \mathrm{m})(n=6)$. i Quantitative RT-PCR analysis of the genes encoding inflammatory cytokines in the WAT of the M/rs2KO mice $(n=6)$. The data are mean \pm SEM. followed by one-way ANOVA with a post hoc test or Student's $t$ test. ${ }^{\star} P<0.05$; ${ }^{\star \star} P<0.01$; ${ }^{\star \star \star} P<0.001$ 
acetyl-CoA carboxylase (ACC), fatty acid synthase (FAS) or stearoyl-CoA desaturase (SCD) 1 between the control and MIrs2KO mice, whereas the expression levels of PPARy, fatspecific protein (FSP) 27 and CD36 were significantly increased in the livers of the HF diet-fed MIrs2KO mice (Supplementary Fig. 3f). The expression levels of the inflammatory cytokines in the liver were also significantly elevated in the HF diet-fed MIrs2KO mice (Supplementary Fig. 3g). In the WAT, while the adipocyte cell size was similar between the control and MIrs $2 \mathrm{KO}$ mice, F4/80-positive crown-like structures (CLS) were significantly increased in the HF diet-fed MIrs2KO mice (Fig. 1g, h). Moreover, the expression levels of the inflammatory cytokines were also significantly increased in the WAT obtained from these mice (Fig. 1i). These data suggest that a lack of Irs2 in the MФs causes insulin resistance and inflammation in both the liver and the WAT under the HF diet condition.

Irs2 deficiency impaired M2a $\Phi$ activation in obesity. To investigate whether the polarization of $M \Phi s$ is altered in the HF diet-fed MIrs2KO mice, the M1- and M2-type MФs were analyzed by flow cytometry. Consistent with the results of the histological analyses (Fig. 1h), the percentage of siglecF-CD11b ${ }^{+} \mathrm{F} 4 /$ $80^{+}$cells was significantly increased in the WAT of the HF dietfed MIrs2KO mice (Fig. 2a). Although the Irs2 expression levels in the siglecF- $\mathrm{CD}^{-} 1 \mathrm{~b}^{+} \mathrm{F} 4 / 80^{+}$cells of the MIrs $2 \mathrm{KO}$ mice were markedly reduced, the expression levels of $I R, I L-4 R$ and STAT6 did not differ between the control and MIrs2KO mice under the HF diet condition (Supplementary Fig. 4a). The HF diet-fed MIrs2KO mice showed an increase in the number of CD11cpositive cells and decrease in the number of CD206-positive cells in the ATMs (Fig. 2a). The M1/M2 ratio was significantly increased in the adipose tissue of the HF diet-fed MIrs2KO mice (Fig. 2a). Consistent with these results, the M2a-subtype MФ marker genes were downregulated, whereas some of the M1-type $\mathrm{M} \Phi$ marker genes were upregulated in the siglecF $\mathrm{F}^{-} \mathrm{CD} 11 \mathrm{~b}^{+} \mathrm{F} 4 / 80$ + cells of the MIrs2KO mice (Fig. 2b). The expression levels of $I L-$ 10 , which is predominantly expressed in M2b-subtype MФs, were not significantly different between the control and MIrs2KO mice. The percentage of siglecF $\mathrm{F}^{+}$cells in the SVCs were also not significantly different between the control and MIrs2KO mice (Supplementary Fig. 4b). These data suggest that the lack of Irs2 in the MФs led to an increase in the number of M1-type MФs and the M1/M2 ratio, and a decrease in the number of M2a-subtype $M \Phi s$ in the WAT, resulting in the aggravation of insulin resistance in the MIrs2KO mice under the HF diet condition.

Why did the M1/M2 ratio increase in the WAT of the HF dietfed MIrs2KO mice? Since M2a-subtype MФs are activated by both IL- 4 and IL-13 ${ }^{18}$, we investigated whether it is IL- 4 or IL-13 that regulates the M2a-subtype $\mathrm{M} \Phi$ marker gene expressions through Irs2. The expression levels of Arg1, FIZZ1, Ym1 and $M \Phi$ galactose $\mathrm{N}$-acetyl-galactosamine-specific lectin 1 (Mgl1), which are hallmarks of activated M2a-subtype MФs, were significantly reduced in the BMDM of the MIrs2KO mice after IL-4 stimulation (Fig. 2c). Consistent with these data, IL-4-induced arginase activity was also impaired in the BMDM of the MIrs2KO mice (Fig. 2d). In marked contrast, the expression levels of these marker genes after IL-13 stimulation were similar between the control and MIrs2KO mice (Supplementary Fig. 4c). There were no significant differences in the IL- 4 and IL-13 levels in the WAT between the control and MIrs2KO mice under the HF diet condition (Supplementary Fig. 4d). These data suggest that IL-4induced, but not IL-13-induced, M2a-subtype MФ activation is impaired in the MIrs2KO mice. There were no significant differences in LPS-induced M1-type activation or MCP-1induced BMDM migration between the control and MIrs2KO mice (Fig. 2e and Supplementary Fig. 4e). Although IL-4 has been reported to regulate the proliferation of tissue-resident $\mathrm{M}^{24}$, IL-4-induced BMDM proliferation did not differ between the control and MIrs2KO mice (Supplementary Fig. 4f). We then constructed a co-culture system of BMDM derived from MIrs2KO mice and 3T3-L1 cells. The IL-4 levels were increased in the conditioned medium of the 3T3-L1 cells, but not BMDM (Supplementary Fig. 4g), suggesting that IL-4 was secreted from the 3T3-L1 cells. There was no significant difference in the IL-4 level in the conditioned medium between the BMDM of the control and MIrs2KO mice in co-culture (Supplementary Fig. 4g). The CCR2 and IL-6 expression levels in the 3T3-L1 cells were significantly higher than those in the BMDM from the MIrs2KO mice than in the BMDM derived from control mice (Fig. 2f). These data suggest that impairment of IL-4-induced M2a-subtype $\mathrm{M} \Phi$ activation in the BMDM is responsible for the increased M1/ $\mathrm{M} 2$ ratio in the HF diet-fed MIrs2KO mice.

We next investigated the molecule mechanisms of IL-4induced M2a-subtype $M \Phi$ activation via Irs2. Although IL-4induced phosphorylation of Irs2 in the BMDM of the control mice, this phosphorylation was undetectable in the BMDM of the MIrs2KO mice (Fig. 2g). Moreover, treatment with LY294002, a PI3 kinase inhibitor, significantly inhibited the phosphorylation of Akt induced by IL-4 in the BMDM (Fig. 2h). IL-4-induced Akt phosphorylation was significantly decreased in the BMDM of the MIrs2KO mice (Fig. 2i). Consistent with this result, the expression levels of Arg1, FIZZ1, Ym1 and Mgl1 induced by IL4 were significantly suppressed by LY294002 treatment (Fig. 2j). We next examined whether FoxO1 phosphorylation is regulated by IL-4 in the BMDM. FoxO1 was phosphorylated by IL-4, and this phosphorylation was inhibited by LY294002 treatment (Supplementary Fig. 4h). Moreover, immunohistochemical staining revealed that FoxO1 was translocated from the nucleus to the cytoplasm after IL-4 stimulation, and that this translocation was inhibited by LY294002 treatment (Supplementary Fig. 4i). Consistent with these data, we found that after IL-4 stimulation, the FoxO1 protein levels were decreased in the nuclear fraction, whereas they were increased in the cytoplasmic fraction (Supplementary Fig. 4j). We then investigated whether FoxO1 is involved in M2a-subtype $M \Phi$ activation. Transfection of constitutively active (CA) FoxO1 significantly reduced the expression levels of Arg1, FIZZ1, Ym1 and Mgl1 induced by IL4 stimulation (Fig. 2k). IL-4-induced FoxO1 phosphorylation was significantly reduced in the BMDM of the MIrs2KO mice as compared to the control mice (Fig. 21), and the decreased expression levels of the M2a-subtype marker genes in the BMDM of the MIrs2KO mice were completely restored by siFoxO1 treatment (Fig. $2 \mathrm{~m}$ ). The $I L-10$ and TNF $\alpha$ expression levels were significantly decreased by IL-4 stimulation and their gene expression levels did not differ among the three groups. Although the $I L-1 \beta$ expression levels were also significantly decreased by IL4 stimulation in all three groups, the transfection of siFoxO1 reduced the expression levels of $I L-1 \beta$ before IL- 4 stimulation in the BMDM of the MIrs2KO mice. No $I L-12 a$ or $I L-12 b$ expression was detected in the BMDM (Supplementary Fig. 4k). These data suggest that IL-4 regulates the PI3 kinase-FoxO1 pathway via Irs2, which is essential for the activation of M2a-subtype MФs.

The FoxO1/NCoR1/HDAC3 complex suppressed M2a $\Phi$ activation. To explore the mechanisms underlying FoxO1 mediation of M2a-subtype $M \Phi$ activation induced by IL- 4 treatment, we measured the Arg1 promoter activity with or without CA-FoxO1 treatment using RAW264.7 cells. We first confirmed that the Irs2 protein was expressed, and then that IL-4-induced M2a-subtype MФ activation and that this activation was inhibited by LY294002 
a

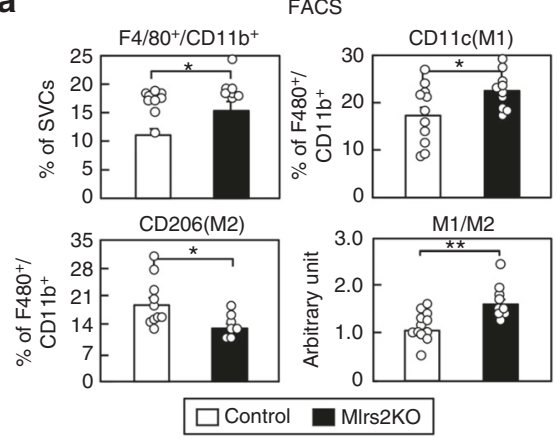

b

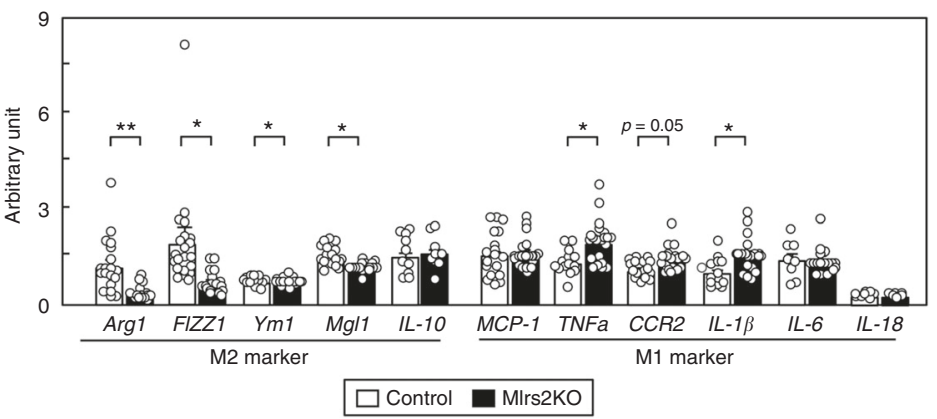

C

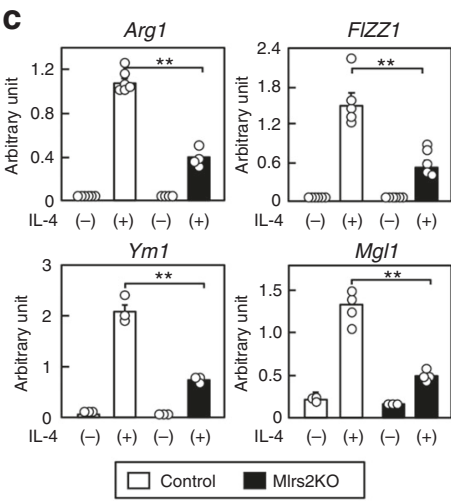

g

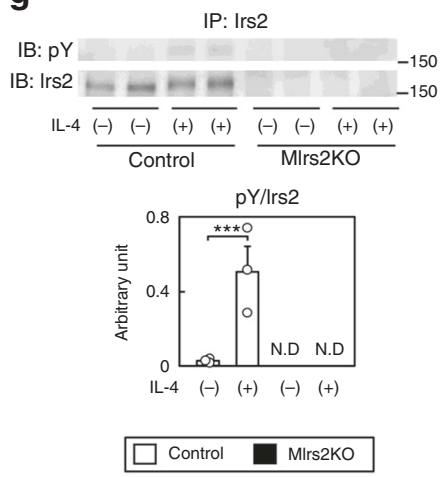

d Arginase activity
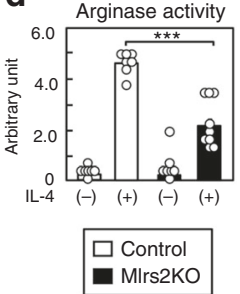
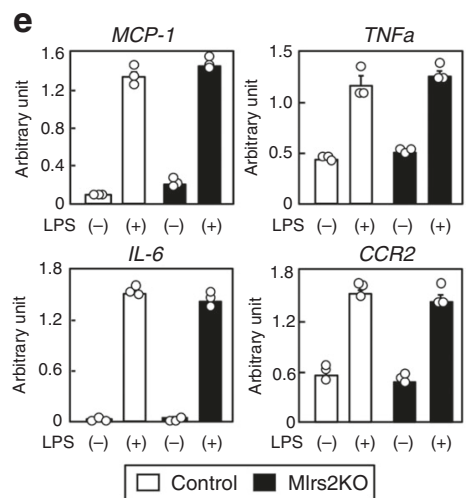

$\square$ Control $\square$ Mlrs2KO

i

h
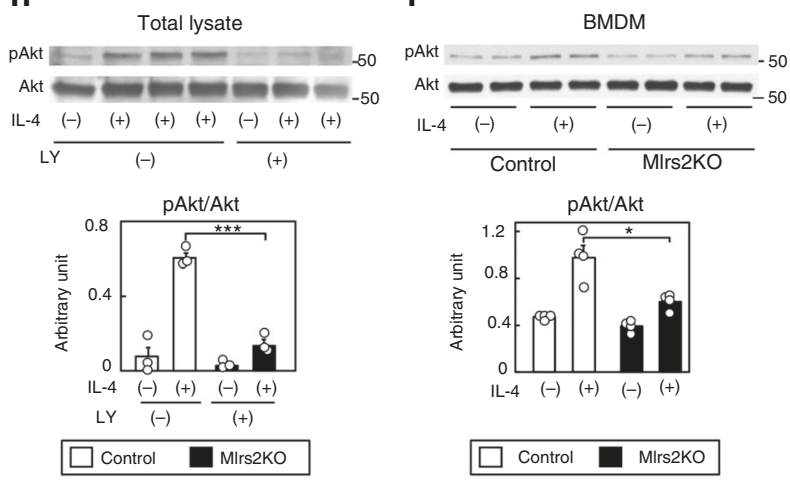

$\mathbf{k}$
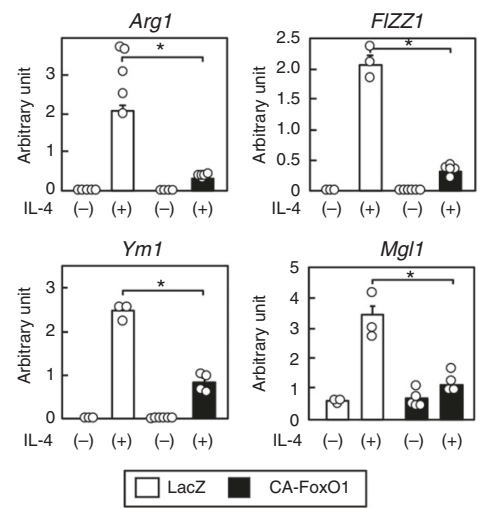

I
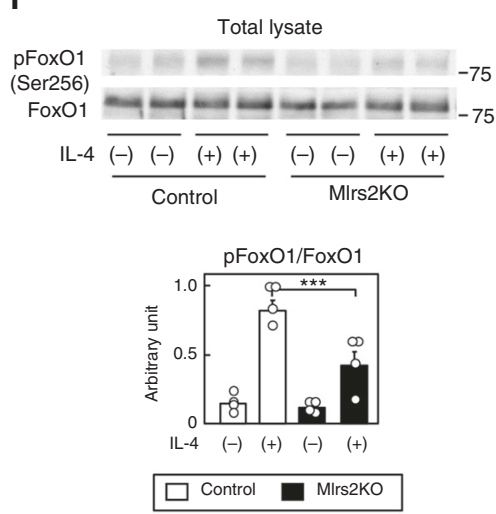
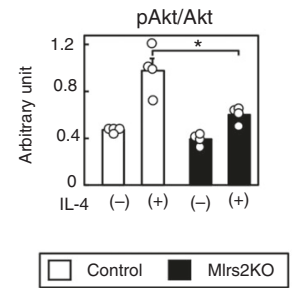
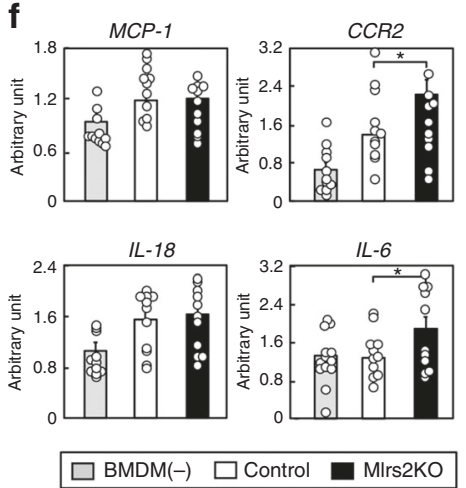
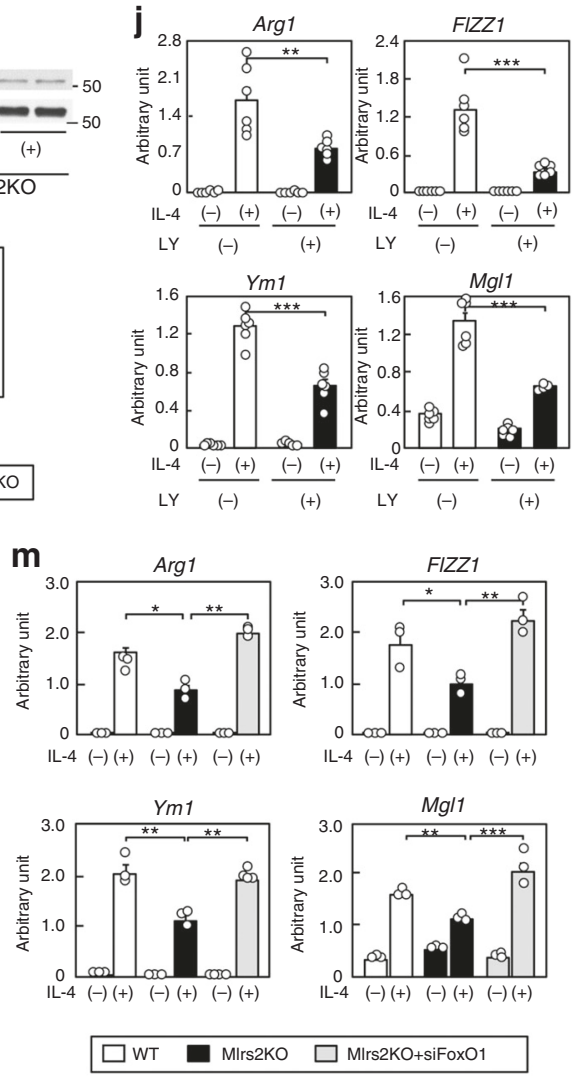

treatment in the RAW264.7 cells (Supplementary Fig. 5a, b). We created Arg1 luciferase constructs including enhancer elements and proximal promoter fragments on the basis of a previous report $^{25}$. The enhancer elements contained the STAT6 response element, which is considered as a STAT6-binding site. Although the Arg1 promoter activity was significantly increased after IL-4 stimulation, this increase was suppressed by CA-FoxO1 treatment
(Fig. 3a). These data suggest that FoxO1 directly regulates IL-4induced Arg1 transcript activation. Since we found two FoxO1 consensus sequences in the promoter area of the Arg1 constructs, we created an Arg1 construct with either A (GTAAATAA $\rightarrow$ GTCGATAA) or B (AAAACAA $\rightarrow$ TCTAGACA) area mutation. Mutant A promoter activity was significantly increased after IL-4 stimulation, and this increase was suppressed by CA-FoxO1 


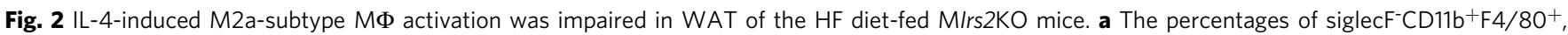

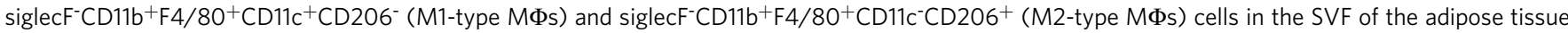
$(n=10-14)$. $\mathbf{b}$ Expression levels of M2-type and M1-type $M \Phi$ marker genes in the siglecF-CD11 ${ }^{+} F 4 / 80^{+}$cells in the SVF of the adipose tissue from the control and M/rs2KO mice $(n=10-14)$. c Expression levels of M2a-subtype M $\Phi$ marker genes in the BMDM of the control and M/rs2KO mice after IL-4 stimulation for $48 \mathrm{~h}(n=6-8)$. d Arginase activity in the BMDM of the control and M/rs2KO mice after IL-4 stimulation for $24 \mathrm{~h}(n=7-10)$. e Expression levels of the M1-type M $\Phi$ marker genes in the BMDM of the control and MIrs2KO mice after LPS stimulation for $48 \mathrm{~h}(n=3)$. f MCP-1, CCR2, IL-18 and IL-6 expression levels in 3T3-L1 cells in co-culture with the BMDM of M/rs2KO mice $(n=12)$. $\mathbf{g}$ Irs2 phosphorylation and protein levels in the BMDM of the control and Mlrs2KO mice after IL-4 stimulation $(n=3-4)$. h Akt phosphorylation and protein levels in the BMDM of the C57BL/6 mice after IL-4 stimulation with or without LY294002 treatment $(n=3)$. i IL-4-induced Akt phosphorylation in the BMDM of the Mlrs $2 \mathrm{KO}$ mice $(n=4)$. $\mathbf{j}$ Expression levels of the M2a-subtype M $\Phi$ marker genes in the BMDM of the C57BL/6 mice after IL-4 stimulation with or without LY294002 treatment ( $n=4-6$ ). k Expression levels of the M2a-subtype M $\Phi$ marker genes in the BMDM of the C57BL/6 mice after IL-4 stimulation with or without CA-FoxO1 treatment $(n=4-6)$. I FoxO1 phosphorylation and protein levels in the BMDM of the control and M/rs2KO mice after IL-4 stimulation $(n=3-4)$. $\mathbf{m}$ Expression levels of the M2a-subtype M $\Phi$ marker genes in the BMDM of the M/rs2KO mice after IL-4 stimulation with siFoxO1 transfection $(n=5-6)$. The data are mean \pm SEM. followed by one-way ANOVA with a post hoc test or Student's $t$ test. ${ }^{\star} P<0.05 ;{ }^{\star \star} P<0.01 ;{ }^{\star \star \star} P<0.001$

treatment (Fig. 3a, b; left panel); on the other hand, mutant B and mutant A plus B promoter activities were not inhibited by CAFoxO1 treatment (Fig. 3a, b; middle and right panel). These data suggest that FoxO1 directly binds to consensus sites including the $\mathrm{B}$ area, and suppresses Arg1 transcript activation induced by IL-4. Since FoxO1 is known to form a corepressor complex with HDAC and NCoR1 in the central nervous system ${ }^{26}$, we investigated whether FoxO1 forms a corepressor complex with HDAC3 and NCoR1 in the RAW264.7 cells by using the electrophoretic mobility shift assay (EMSA). The EMSA revealed that DNA nucleotides of the B area in the Arg1 promoter bind to proteins, and that the DNA-protein complexes were blocked or gel-shifted in a dose-dependent manner by FoxO1, HDAC3 or NCoR1 antibody (Fig. 3c). Moreover, we performed Chip-qPCR using FoxO1, HDAC3 or NCoR1 antibody in the Raw 264.7 cells and BMDM. Although the Arg1 expression levels were significantly increased before IL- 4 stimulation, these increases were inhibited after IL-4 stimulation in both the Raw 264.7 cells and BMDM (Fig. 3d and Supplementary Fig. 5c). These data suggest that FoxO1 forms a corepressor complex with HDAC3 and NCoR1, and that this corepressor complex suppresses Arg1 transcript activation. Moreover, we performed the Chip-qPCR assay in the BMDM of the MIrs2KO mice. Although the Arg1 expression levels were significantly increased before IL-4 stimulation, these increases were not inhibited after IL-4 stimulation in the BMDM of the MIrs $2 \mathrm{KO}$ mice (Fig. 3e). There were no significant differences in the FoxO1, HDAC3 or NCoR1 expression levels in the ATMs between the control and MIrs2KO mice (Supplementary Fig. 5d). These data suggest that Irs2 is essential for IL-4-induced dissociation of the FoxO1/HDAC3/NCoR1 corepressor complex in vivo. To investigate whether FoxO1 directly binds to HDAC3 and NCoR1, we conducted co-immunoprecipitation (Co-IP) with FoxO1, HDAC3, or NCoR1 antibody without IL-4 stimulation in the Raw 264.7 cells and BMDM. Co-IP with FoxO1 detected HDAC3 and NCoR1, Co-IP with HDAC3 detected FoxO1 and NCoR1, and Co-IP with NCoR1 detected FoxO1 and HDAC3 in both the Raw 264.7 cells and BMDM (Fig. 3f). These data suggest that FoxO1 directly binds to HDAC3 and NCoR1. Moreover, IL4-induced Arg1 expression was significantly increased in the BMDM transfected with siHDAC3 or siNCoR1 (Fig. 3g). In addition to $A r g 1$, the FIZZ1 and $Y m 1$ promoter activities were also significantly increased after IL-4 stimulation, although these increases were suppressed by CA-FoxO1 (Supplementary Fig. 5e). IL-4-induced FIZZ1 and Ym1 expressions were significantly increased in the BMDM transfected with siHDAC3 or siNCoR1 (Supplementary Fig. 5f). The TNF $\alpha$ and $I L-1 \beta$ expression levels were significantly decreased by IL-4 stimulation, while their gene expression levels did not differ between the BMDM transfected and not transfected with siHDAC3 or siNCoR1. No $I L-12 a$ or $I L-$
$12 b$ expression was detected in the BMDM (Supplementary Fig. 5g). These data suggest that FoxO1 directly binds to HDAC3 and NCoR1 and forms a corepressor complex, leading to suppression of M2a-subtype M $\Phi$ activation.

MIRKO mice exhibit improved insulin sensitivity. Irs2 is known as a substrate for not only IL-4R, but also IR. Myeloid cell-specific $I L-4 R \alpha$-deficient $(\mathrm{M} I L-4 R \mathrm{KO})$ mice showed decreased M2a-subtype $\mathrm{M} \Phi$ activation and insulin sensitivity, just like the MIrs $2 \mathrm{KO}$ mice ${ }^{16}$. Thus, we next generated and investigated the phenotypes of $\mathrm{MIRKO}$ mice. As compared to the MIrs2KO mice, the glucose tolerance was significantly better and the plasma insulin levels significantly lower in the MIRKO mice, although there was no significant difference in the BW gain between the two models of mice (Fig. 4a and Supplementary Fig. 6a). The MIRKO mice showed increased GIR and reduced EGP in the hyperinsulinemiceuglycemic clamp study (Fig. 4b). The phosphorylation levels of Akt in the liver and WAT, but not in the skeletal muscle, were significantly increased in the MIRKO mice after insulin infusion via the vena cava (Fig. 4c). These data suggest that the MIRKO mice show an improvement of the hepatic and WAT insulin resistance under the HF diet condition. Consistent with these data, PTT revealed that the blood glucose levels were lower in the MIRKO mice than in the control mice, and that PEPCK and G6Pase expression levels were significantly reduced in the livers of the MIRKO mice (Supplementary Fig. 6b, c). The TG content and gene expression levels associated with lipogenesis were significantly decreased in the livers of the MIRKO mice (Supplementary Fig. 6d, e). Moreover, the MIRKO mice also showed a reduction in the expression levels of the inflammatory cytokines in the liver (Supplementary Fig. 6f). In the WAT of the HF diet-fed MIRKO mice, the number of F4/80-positive CLS was significantly decreased, although there was no significant change of the adipocyte cell size (Fig. 4d, e). The HF diet-fed MIRKO mice showed decreased inflammatory cytokine expression levels in the WAT (Fig. 4f). Moreover, the number of CD206-positive cells was increased, while the proportions of siglecF $\mathrm{CD}^{-} 1 \mathrm{~b}^{+} \mathrm{F} 4 / 80^{+}$cells, CD11c-positive cells and the M1/M2 ratio were decreased in the WAT of the HF diet-fed MIRKO mice (Fig. 4g). Consistent with these results, the M2a-subtype MФ maker genes were upregulated, whereas some of M1-type MФ marker genes were downregulated in the siglecF$\mathrm{CD} 11 \mathrm{~b}^{+} \mathrm{F} 4 / 80^{+}$cells of the HF diet-fed MIRKO mice (Fig. 4h). The expression levels of $I L-10$ were not significantly different between the control and MIRKO mice. The percentage of siglec $\mathrm{F}^{+}$cells in the SVCs, and the IL-4 and IL-13 levels in the WAT did not differ between the control and MIRKO mice under the HF diet condition (Supplementary Fig. 6g, h). Although the $I L-4 R$ and Irs 2 mRNA expression levels in the BMDM did not differ between the control 
a
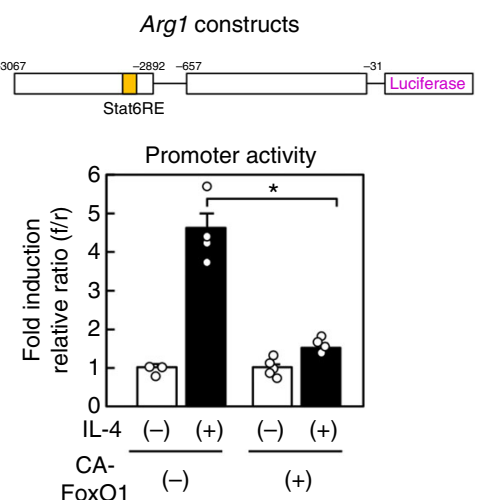

C

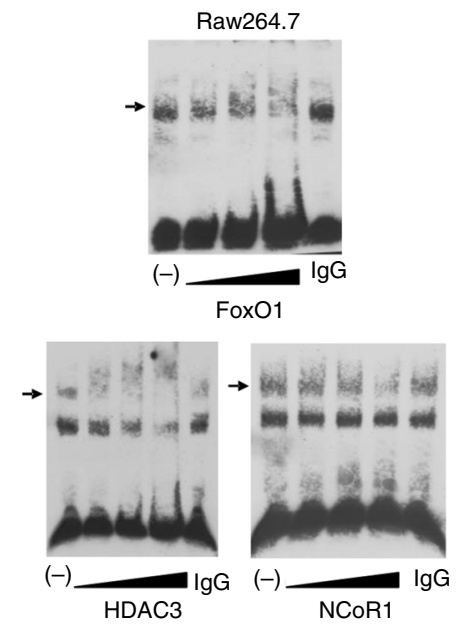

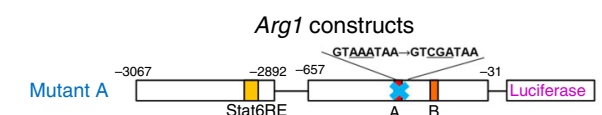

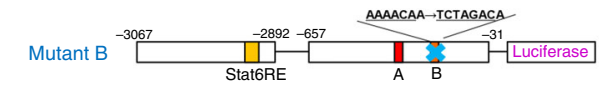

Mutant $\mathrm{A}$ and $\mathrm{B} \underset{\text { Stat6RE }}{-3067} \underbrace{-2892-657}_{\mathrm{A}}]^{-31}$ Luciferase
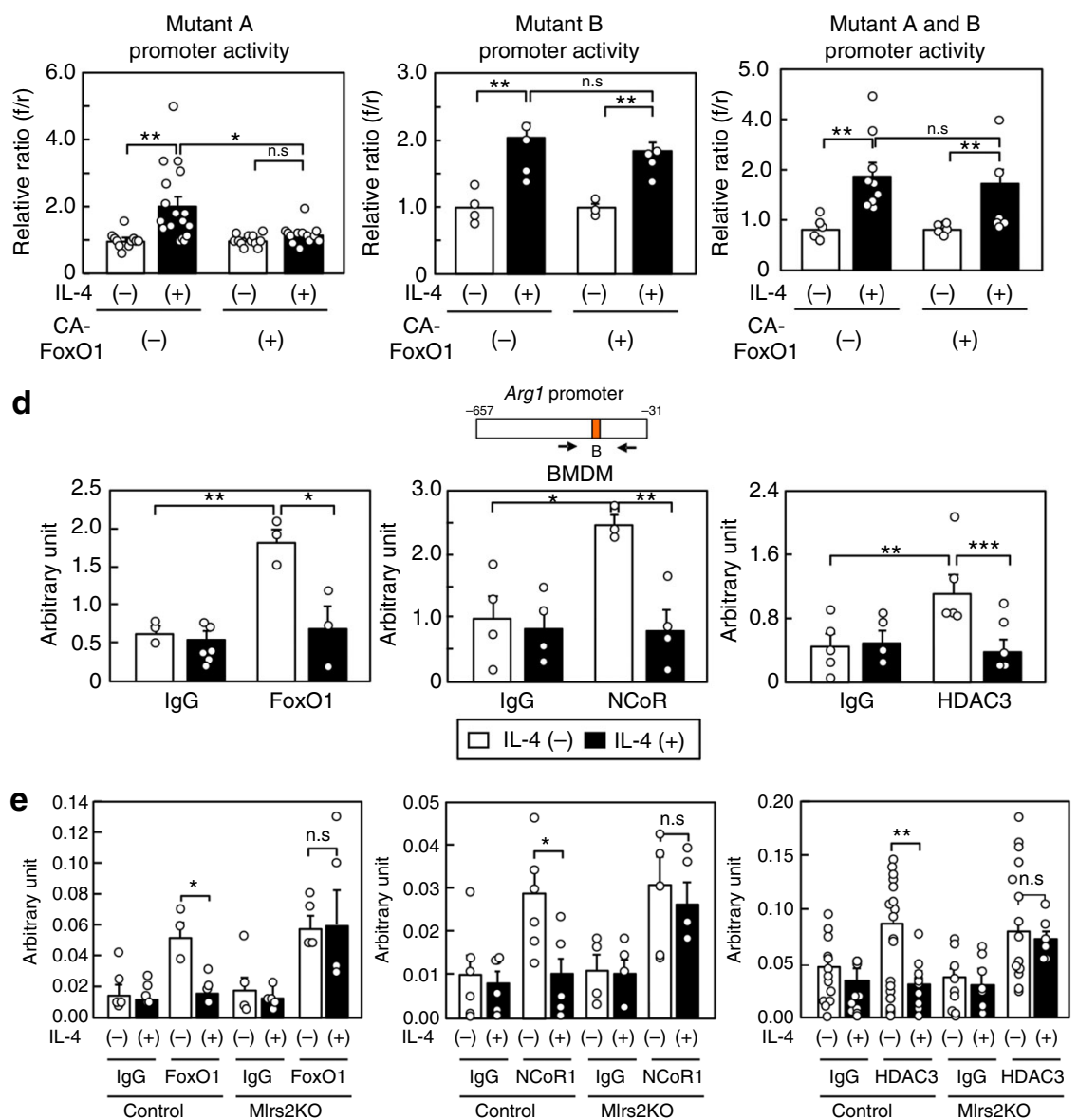

g

f
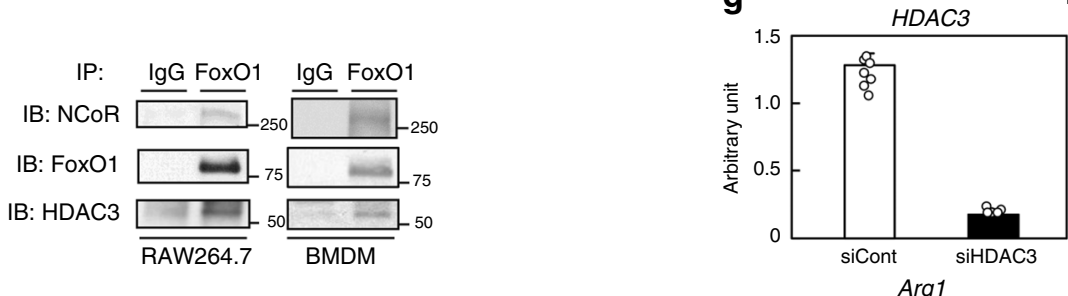

$20 \quad N C o R 1$

IP: IgG HDAC3 IgG HDAC3
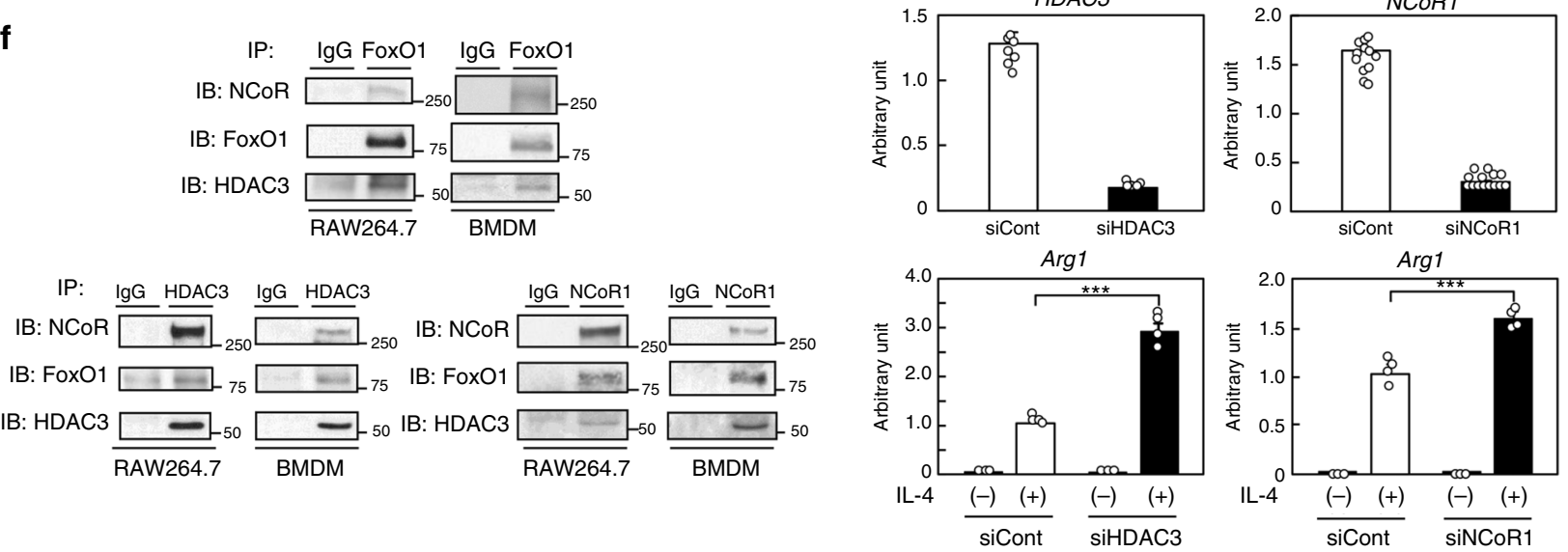

Fig. 3 FoxO1 bound to HDAC3 and NCoR1 to form a corepressor complex. a Arg1 promoter activity after IL-4 stimulation with or without CA-FoxO1 transfection $(n=4-5)$. b Mutant A, B, and A plus B Arg1 promoter activities after IL-4 stimulation with or without CA-FoxO1 transfection ( $n=5-6)$. c The binding of DNA nucleotides of the B area of the Arg1 promoter and proteins, and the blocking of the DNA-protein complex formation in a dose-dependent manner by FoxO1, HDAC3 and NCoR1 antibody were determined by EMSA in RAW264.7 cells. d Chip-qPCR using FoxO1, HDAC3 and NCoR1 antibody in the BMDM of the C57BL/6 mice before and after IL-4 stimulation $(n=5-10)$. e Chip-qPCR using FoxO1, HDAC3 and NCoR1 antibody in the BMDM of the Mirs2KO mice before and after IL-4 stimulation $(n=3-16)$. f Co-immunoprecipitation (Co-IP) with FoxO1, HDAC3 and NCoR1 antibody without IL-4 stimulation in the Raw 264.7 cells and BMDM. $\mathbf{g}$ Expression levels of Arg1 in the BMDM of the C57BL/6 mice after IL-4 stimulation with siHDAC3 or siNCoR1 transfection $(n=3-8)$. The data are mean \pm SEM. followed by one-way ANOVA with a post hoc test. ${ }^{\star} P<0.05 ;{ }^{\star \star} P<0.01 ;{ }^{\star \star \star} P<0.001$ 
a

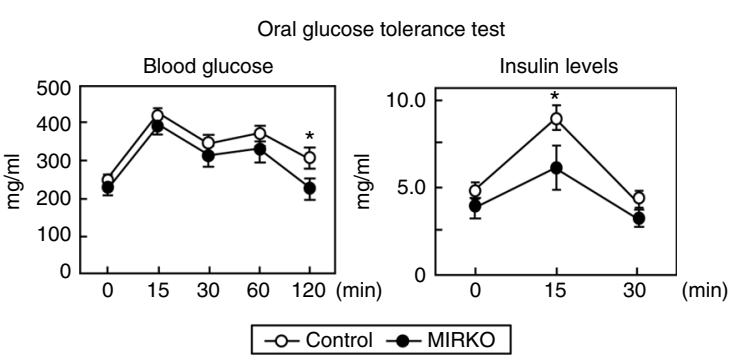

C
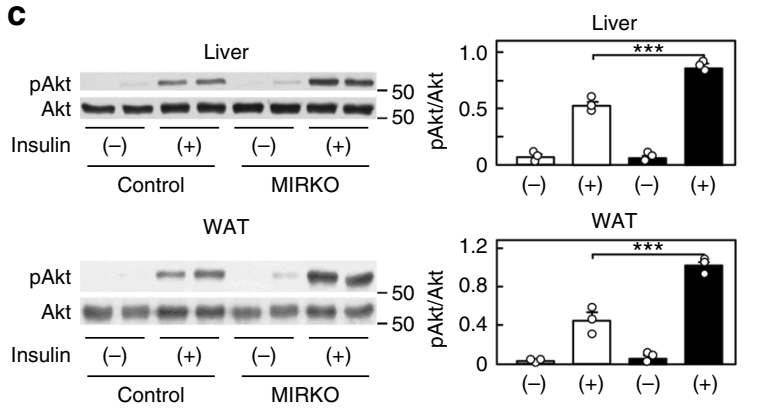

Skeletal muscle
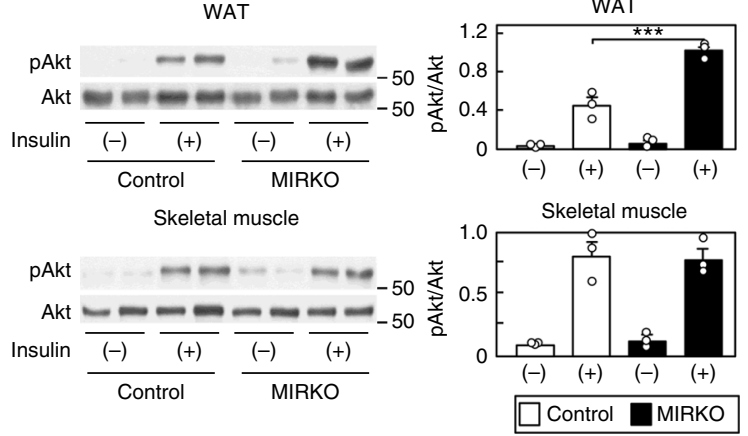

Skeletal muscle
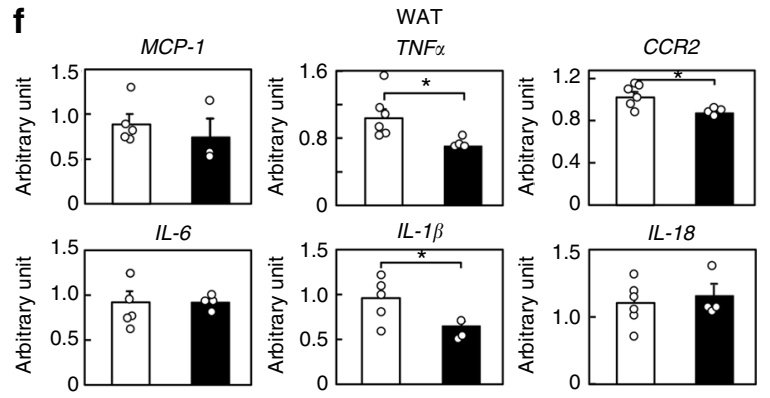

$\square$ Control $\square$ MIRKO b
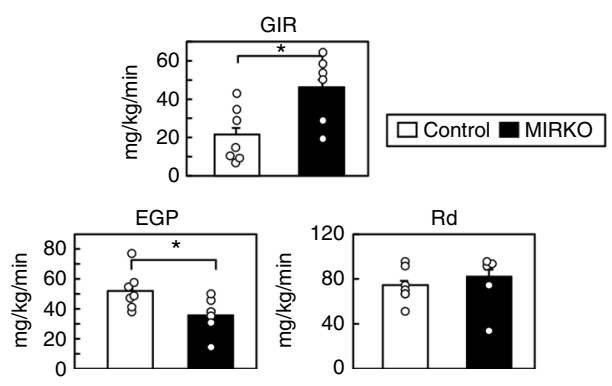

d

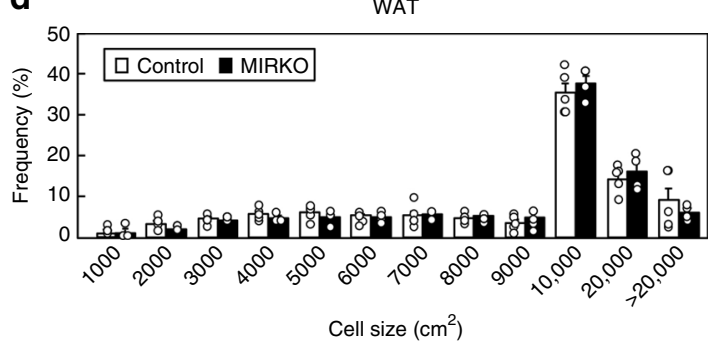

e
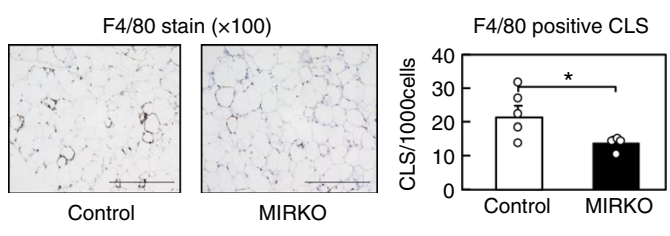

g
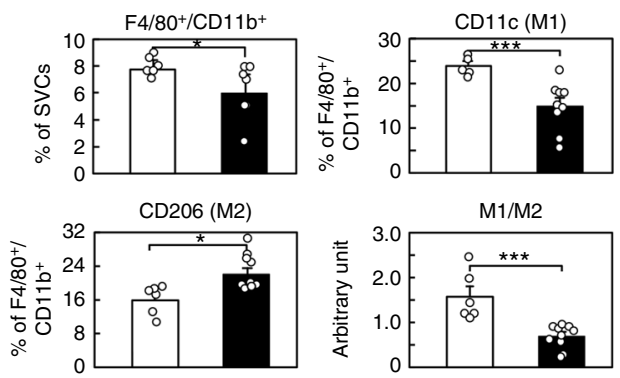

$\square$ Control

h

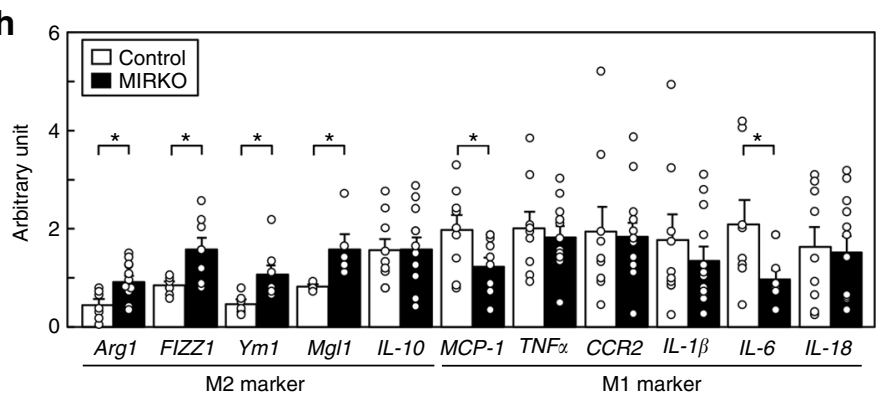

Fig. 4 MIRKO mice exhibited improved insulin sensitivity and glucose tolerance. a Glucose tolerance test in the MIRKO mice ( $n=7-13)$. b GIR, EGP and Rd in the MIRKO mice in the hyperinsulinemic-euglycemic clamp study $(n=8-9)$. c Phosphorylation levels of Akt (ser473) in the liver, WAT and skeletal muscle of the MIRKO mice after insulin infusion $(n=3-4)$. d Adipocyte cell size in the MIRKO mice $(n=4-6)$. e F4/80-positive CLS in the WAT of the MIRKO mice (scale bar, $200 \mu \mathrm{m})(n=4-6)$. f Quantitative RT-PCR analysis of the genes encoding inflammatory cytokines in the WAT of the MIRKO mice

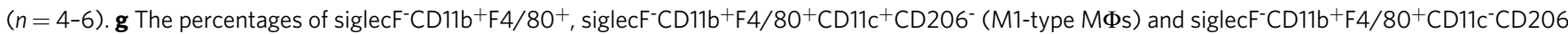

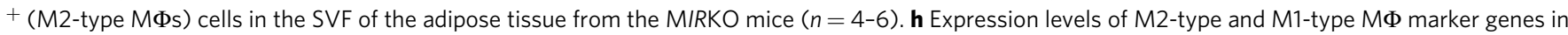
the siglecF-CD11b ${ }^{+} \mathrm{F} 4 / 80^{+}$cells in the SVF of the adipose tissue from the control and MIRKO mice $(n=4-5)$. Data are mean \pm SEM. followed by one-way ANOVA with a post hoc test or Student's $t$ test. ${ }^{\star} P<0.05 ;{ }^{\star \star \star} P<0.001$ 
and MIRKO mice under the NC diet condition, the $I R$ mRNA and protein expressions were almost completely abrogated in the BMDM of the MIRKO mice (Supplementary Fig. 6i, j). There were no significant differences in the BW, ITT, GTT or lipid profiles between the control and MIRKO mice under the NC diet condition (Supplementary Fig. 6k-n). These data suggest that the lack of $I R$ in the MФs led to a decrease in the number of M1-type MФs and the M1/M2 ratio, and an increase in the number of M2a-subtype MФs in the WAT, resulting in the protection of insulin resistance in the MIRKO mice under the HF diet condition.

Irs2 expressions and M2a $\Phi$ activation increased in MIRKO mice. Unlike the MIrs2KO mice, why did the M1/M2 ratio decrease in the WAT of the HF diet-fed MIRKO mice? We analyzed the expression levels of $I R, I r s 2, I L-4 R$, STAT6 in the ATMs of the MIRKO mice. Although the IL-4R and STAT6 expression levels were not significantly different, the expression levels of Irs 2 were significantly higher in the siglecF-CD11 ${ }^{+} \mathrm{F} 4 /$ $80^{+}$cells isolated from the WAT of the MIRKO mice (Fig. 5a). Moreover, the IL-4-induced Irs2 and Akt phosphorylation were significantly enhanced in the peritoneal MФs of HF diet-fed MIRKO mice, along with increased M $\Phi$ Irs2 expression, although IL-4-induced STAT6 phosphorylation did not differ between control and MIRKO mice (Fig. 5b and Supplementary Fig. 7a). These data suggest that M2a-subtype $\mathrm{M} \Phi$ activation was caused by enhanced IL-4-induced Irs2/Akt pathway along with increased Irs2 expression levels in the MIRKO mice reared on a HF diet. IR signaling has been shown to suppress the expression of Irs2, both in vitro and in vivo, by inhibiting the synthesis of Irs 2 mRNA at the transcriptional level in organs such as the liver and endothelial cells $s^{27-30}$. Thus, we investigated the contribution of IR signaling to the expression levels of Irs 2 in the MФs. Transfection of siFoxO1 reduced the Irs2 expression in BMDM (Supplementary Fig. 7b). Although insulin stimulation markedly suppressed the expression of Irs 2 along with translocation of FoxO1 from the nucleus to the cytosol in the BMDM of the control mice (Supplementary Fig. 7c), this downregulation was not observed in the BMDM from the MIRKO mice (Fig. $5 \mathrm{c}$ ). These data suggest that M2a-subtype MФ activation via the IL-4/Irs2 pathway is maintained in MIRKO mice, resulting in reduced inflammation and insulin resistance, as Irs2 expression in the MФs of the MIRKO mice is not downregulated by insulin. We next investigated the expression levels of Irs2 in the peritoneal MФs of the mice after streptozotocin (STZ) plus phlorizin treatment. While the plasma insulin levels were significantly reduced, the peritoneal M $\Phi$ Irs 2 expression levels were significantly increased in the STZ plus phlorizin-treated mice (Supplementary Fig. 7d), suggesting that hyperinsulinemia downregulates $\mathrm{M} \Phi$ Irs2 expression in vivo. Downregulation of Irs2 expression levels by pretreatment with insulin was associated with significantly reduced expressions of IL-4-induced M2a-subtype marker genes in the BMDM, while having no effect on the expression levels of $I R$ and $I L-4 R$ (Fig. $5 \mathrm{~d}$ and Supplementary Fig. 7e). The decreased IL-4-induced Arg1 expression in the BMDM after insulin pretreatment was completely restored by siFoxO1, siNCoR1, or siHDAC3 treatment (Fig. 5e). Moreover, when the BMDM were co-cultured with 3T3L1 cells in the presence of insulin, significant downregulation of the Irs2 expression in the BMDM and significant upregulation of $M C P-1, C C R 2, I L-18$ and $I L-6$ expressions in the 3T3-L1 cells were observed (Fig. $5 \mathrm{f}$ and Supplementary Fig. 7f, g).

M2a $\Phi$ activation is regulated by both Irs2 and STAT6 pathways. Why did insulin fail to induce M2a-subtype $M \Phi$ activation, although it could activate Irs2 as well as IL-4? Although insulin induced phosphorylation of Akt to the same level as that induced by IL-4, it failed to induce M2a-subtype $M \Phi$ activation (Fig. 6a, b). These data suggest that IL-4-induced M2a-subtype M $\Phi$ activation is not mediated by the Irs2/Akt/FoxO1 pathway alone. Since IL-4 is well known to regulate M2a-subtype MФ activation via the STAT6 pathway ${ }^{18}$, we investigated STAT6 phosphorylation induced by IL-4 or insulin stimulation. While IL-4-induced phosphorylation of STAT6, insulin failed to do so (Fig. 6c). As in the case of the BMDM lacking Irs2, IL-4-induced M2a-subtype activation was reduced in the BMDM transfected with siSTAT6 (Fig. 6d). IL-4-induced STAT6 phosphorylation in the BMDM did not differ between the control and MIrs2KO mice, but this phosphorylation was not induced by insulin in the BMDM (Fig. 6e). Moreover, LY294002 treatment inhibited IL-4induced Akt phosphorylation, but had no effect on IL-4-induced STAT6 phosphorylation (Figs. 2h, 6f). Consistent with these data, no differences were found in the expression levels of $P G C 1 \beta$ or PPAR $y$, which are STAT6-associated genes, between the control and MIrs2KO mice after IL-4 treatment (Supplementary Fig. 8). These data suggest that IL-4 regulates M2asubtype MФ activation through both the STAT6 signaling and Irs2/Akt signaling pathways. In contrast, insulin rather suppressed IL-4-induced M2a-subtype MФ activation via downregulation of Irs2.

\section{Discussion}

In this study, we demonstrated that IL-4/Irs2/Akt pathway was essential for activation of M2a-subtype MФs, in addition to IL-4/ STAT6 pathway. Activation of both pathways was necessary for the full activation of M2a-subtype MФs (Fig. 7, left panel). In obesity, although IL-4/STAT6 pathway was preserved, IL-4/Irs2/ Akt pathway was selectively impaired due to downregulation of Irs2 induced by hyperinsulinemia via IR signaling, leading to impaired signaling in the IL-4/Irs2/Akt pathway and M2asubtype МФ activation by stabilization of the FoxO1/HDAC3/ NCoR1 corepressor complex (Fig. 7, right panel). These data suggest that in obesity, hyperinsulinemia plays crucial roles in the dysregulation of M2a-subtype $\mathrm{M} \Phi$ activation due to downregulation of Irs 2 expression.

The chronic hyperinsulinemia induced by sustained overnutrition, such as in animals reared on a HF diet, promotes adipocyte hypertrophy and obesity. In fact, adipose tissue-specific IRKO mice with gold thioglucose (GTG)-induced obesity exhibited a smaller adipocyte size in spite of hyperinsulinemia ${ }^{31}$ Enlarged adipocytes in response to hyperinsulinemia release inflammatory cytokines such as $M C P-1$ and $T N F \alpha$, leading to inflammatory monocytic infiltration of the WAT ${ }^{32}$. The infiltrating monocytes differentiate into M1-type MФs and form CLS around dead adipocytes. The M1-type MФs in the CLS also express inflammatory cytokines, thereby driving the development of insulin resistance. In fact, M1-type MФs were recruited in mice showing overexpression of $M C P$ - 1 in the adipose tissue, resulting in the development of insulin resistance ${ }^{33}$. On the other hand, in this study, we found that hyperinsulinemia downregulated Irs2 expression, which led to impaired M2a-subtype $M \Phi$ activation. These data suggest that chronic hyperinsulinemia causes both increased M1-type $M \Phi$ activation via inducing adipocyte hypertrophy and decreased M2a-subtype $M \Phi$ activation via Irs2 downregulation, thereby leading to the development of inflammation and insulin resistance.

Previous studies have demonstrated that MIRKO mice are protected from obesity-induced inflammation and insulin resistance under the HF diet condition. The obesity-associated MФ infiltration of the adipose tissue was significantly reduced in these mice $^{34}$. On the other hand, mice lacking 3-phosphoinositidedependent protein kinase 1 (PDK1) in the myeloid cells, which are 
a
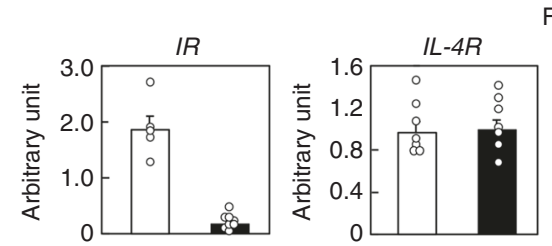

FACS

b
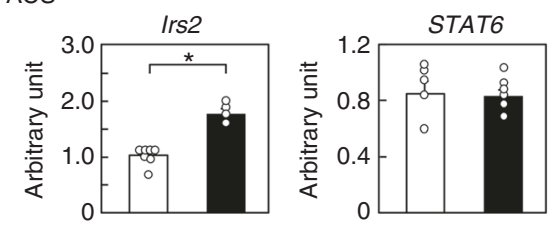

$\square$ Control $\mathbf{M}$ MIRKO

Peritoneal macrophages

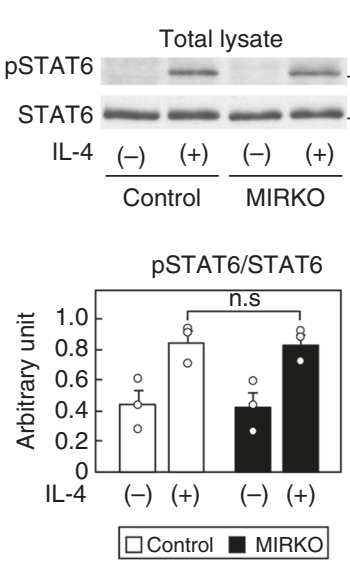

C

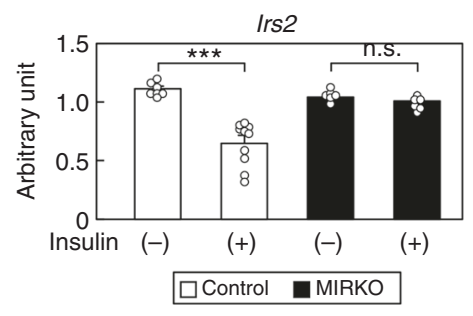

e

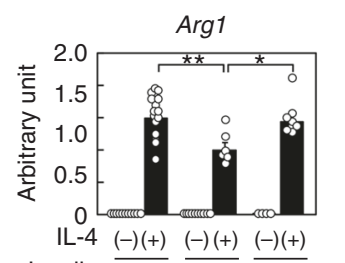

IL-4 $\frac{(-)(+)}{(-)(+)} \frac{(-)(+)}{(-)}$

$\underset{\text { siFoxO1 }}{\operatorname{Insulin}} \frac{(-)}{(-)} \frac{(+)}{(-)} \frac{(+)}{(+)}$

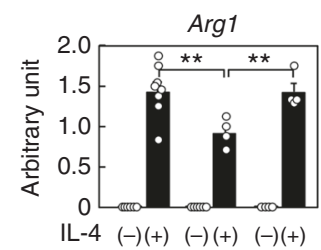

$\underset{\text { IiHDAC3 }}{\operatorname{Insulin}} \frac{(-)}{(-)} \frac{(+)}{(-)} \frac{\frac{(+)}{(+)}}{(+)}$
IP: Irs2

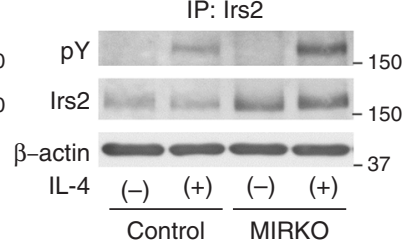

Total lysate

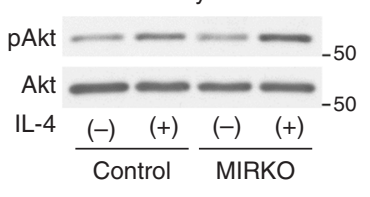

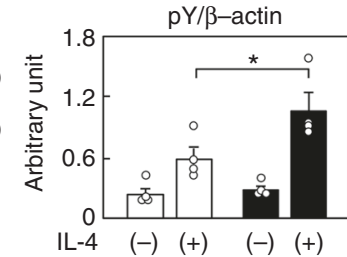
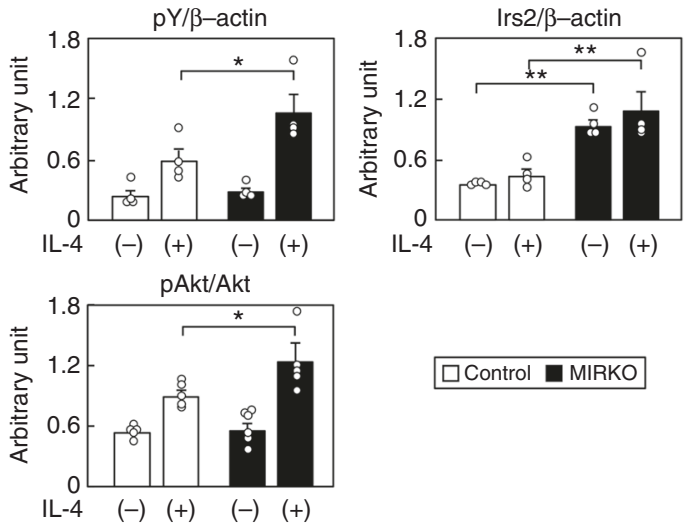

$\square$ Control —MIRKO d
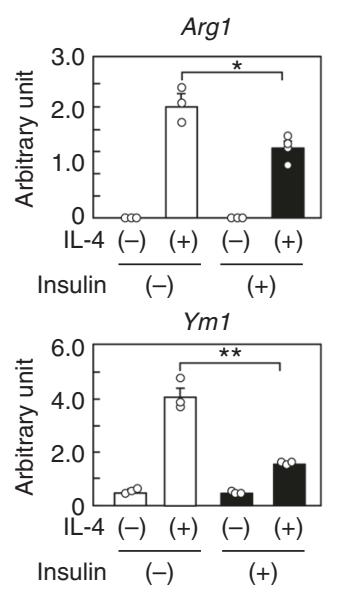

$\mathbf{f}$

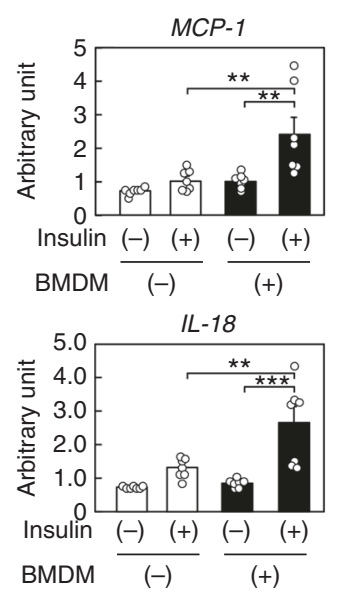

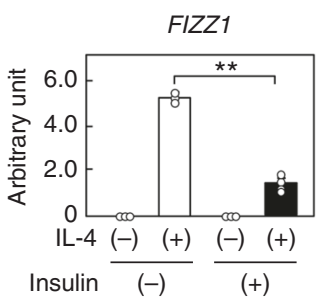
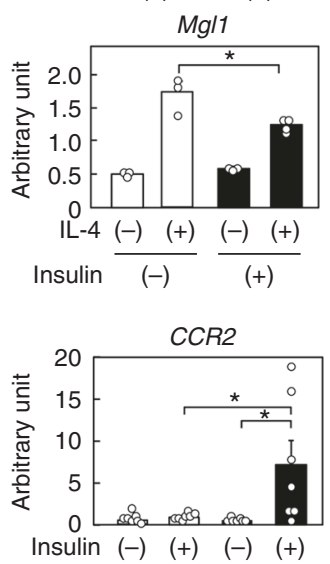

$\operatorname{BMDM} \overline{(-)} \stackrel{(+)}{(+)}$

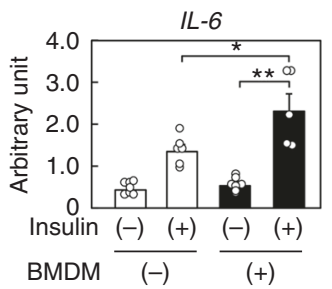

Fig. 5 The Irs 2 mRNA levels and number of M2a-subtype MФs were elevated in HF diet-fed MIRKO mice. a Expression levels of IR, IL-4R, Irs2 and STAT6 in the siglecF-CD11b+F4/80+ cells of the SVF of the adipose tissue from the control and MIRKO mice $(n=4-6)$. b IL-4-induced STAT6, Irs2 and Akt phosphorylation in peritoneal MФs of HF diet-fed MIRKO mice $(n=3-6)$. c Irs2 expression levels in the BMDM of the control and MIRKO mice after 100 $\mathrm{nM}$ insulin stimulation for $3 \mathrm{~h}(n=3-4)$. d IL-4-induced M2a-subtype marker genes in the BMDM after $100 \mathrm{nM}$ insulin pretreatment for $8 \mathrm{~h}(n=3-4)$. e IL4-induced Arg1 expression levels in the BMDM pretreated with $100 \mathrm{nM}$ insulin for $8 \mathrm{~h}$ after siFoxO1, siNCoR1, or siHDAC3 treatment $(n=4-16)$. f MCP-1, CCR2, IL-18 and IL-6 expression levels in 3T3-L1 cells in co-culture with BMDM of the C57BL/ 6 mice and 3T3-L1 cells after insulin stimulation for $24 \mathrm{~h}$ ( $n=$ 7). The data are mean \pm SEM. followed by one-way ANOVA with a post hoc test or Student's $t$ test. ${ }^{\star} P<0.05 ;{ }^{\star \star} P<0.01$; ${ }^{\star \star \star} P<0.001$ 
a
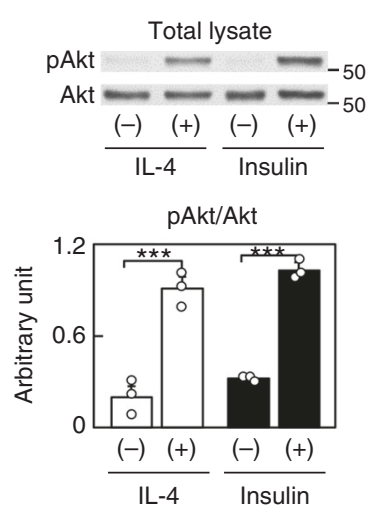

b
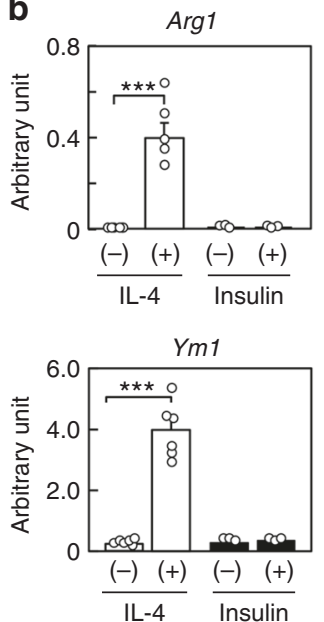

d

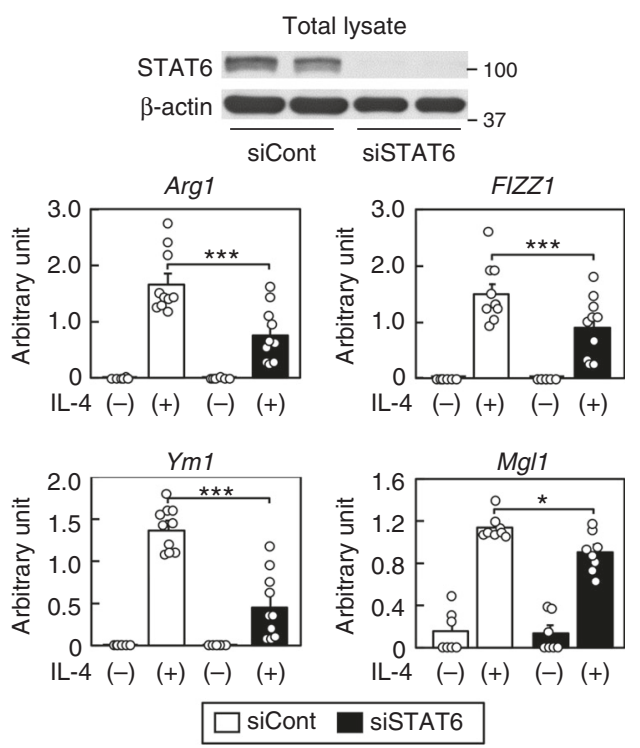

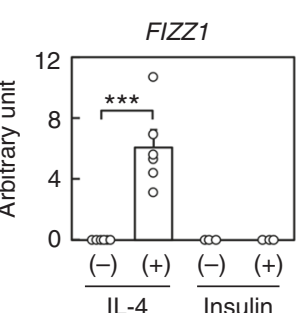

C
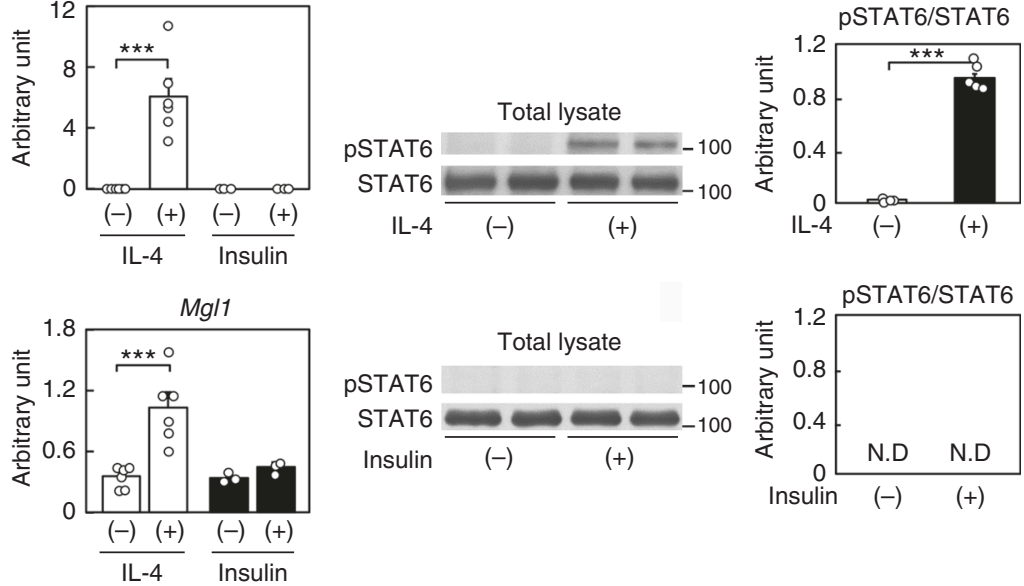

e

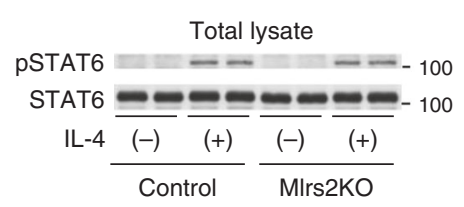

Total lysate

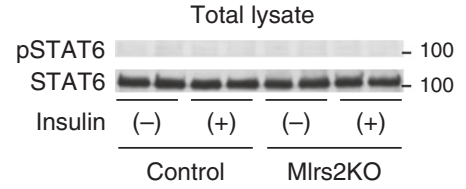

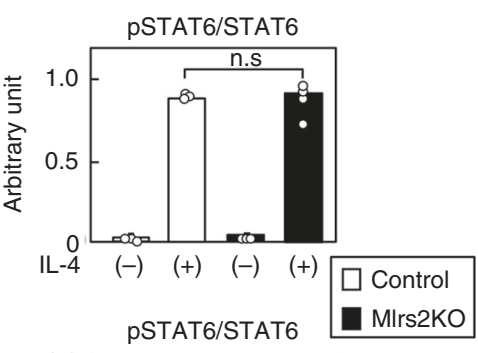

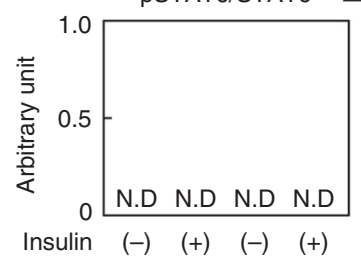

f
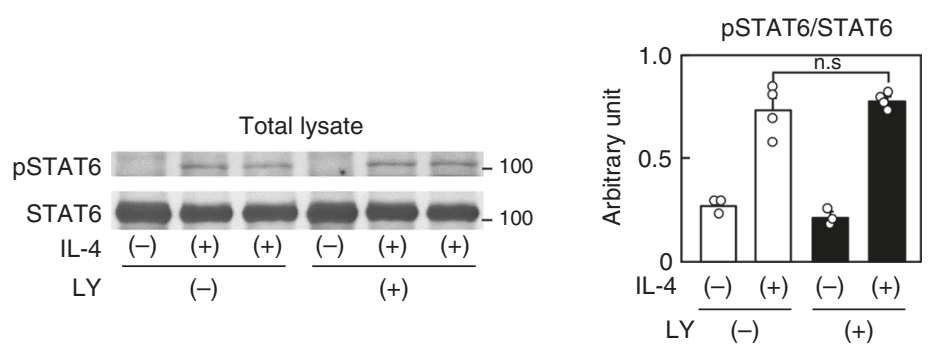

Fig. 6 IL-4-induced M2a-subtype M $\Phi$ activation was regulated by both the Irs2 and STAT6 pathways. a Akt phosphorylation and protein levels in the BMDM of the C57BL/6 mice after IL-4 or insulin stimulation $(n=3-4)$. $\mathbf{b}$ Expression levels of the M2a-subtype M $\Phi$ marker genes in the BMDM of the C57BL/ 6 mice after IL-4 or insulin stimulation $(n=4)$. c STAT6 phosphorylation and protein levels in the BMDM of the C57BL/6 mice after IL-4 or insulin stimulation $(n=3-4)$. d Expression levels of the M2a-subtype M $\Phi$ marker genes in the BMDM of the C57BL/6 mice after IL-4 stimulation following siSTAT6 transfection $(n=5-6)$. e STAT6 phosphorylation and protein levels in the BMDM of the control and M/rs2KO mice after IL-4 or insulin stimulation $(n=3-4)$. f STAT6 phosphorylation and protein levels in the BMDM of the C57BL/6 mice after IL-4 stimulation following LY294002 treatment $(n=4)$. N. $D$ not-detected. The data are mean \pm SEM. followed by one-way ANOVA with a post hoc test. ${ }^{\star} P<0.05 ;{ }^{\star \star \star} P<0.001$

downstream signaling molecules in the IR/Irs2 pathway, showed adipose tissue inflammation and insulin resistance under the HF diet condition ${ }^{35}$. The results from the MIRKO mice suggest that impaired insulin signaling in $M \Phi s$ improved obesity-induced inflammation and insulin resistance. On the other hand, impaired insulin signaling in the $\mathrm{M} \Phi$ s of $P D K 1 \mathrm{KO}$ mice aggravated inflammation and insulin resistance. Thus, in terms of the effects of insulin signaling, there seem to be discrepancies in the phenotypes between the MIRKO and PDK1KO mice. However, this could be interpreted by analyzing the effects of IL- 4 signaling in an integrated fashion. As seen in this study (Fig. 7), in the MIRKO mice, MФ Irs2 downregulation by insulin is suppressed and $\mathrm{M} 2 \mathrm{a}$-subtype $\mathrm{M} \Phi$ activation via the IL-4 signaling pathway is preserved. Although MФ Irs2 downregulation by insulin may also be suppressed in the PDK1KO mice, as in the MIRKO mice, the IL-4 signaling pathway in the MФs is impaired downstream of Irs2 

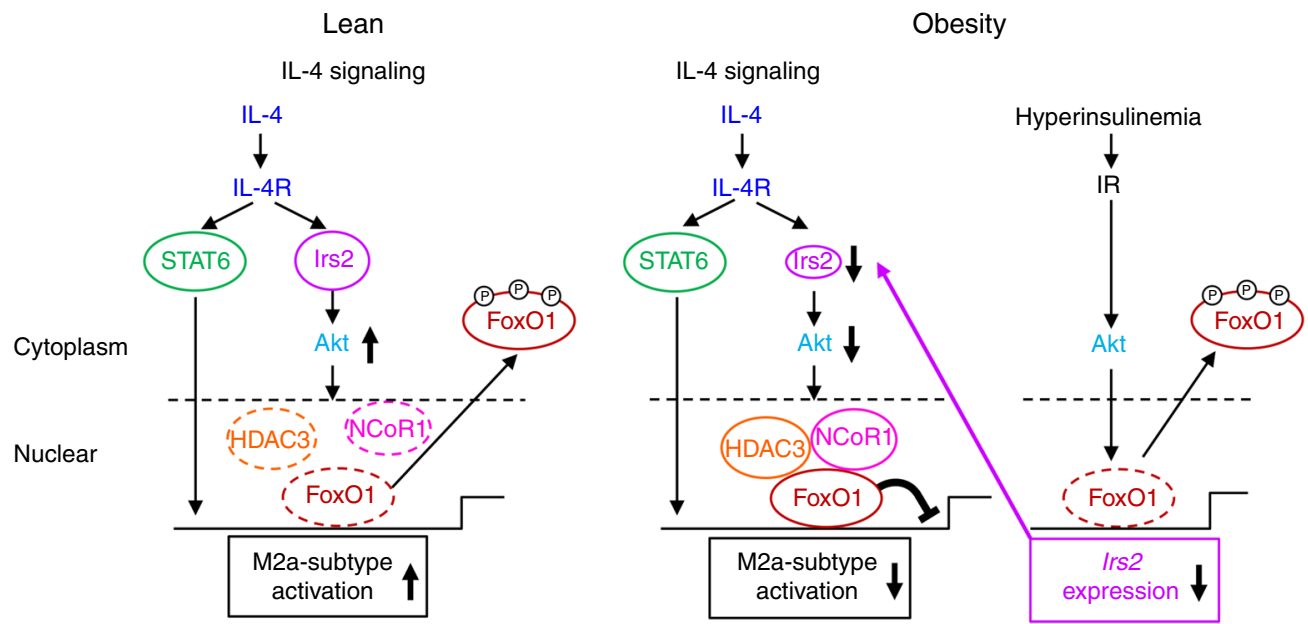

Fig. 7 Scheme illustrating the mechanism of impaired IL-4-induced M2a-subtype M $\Phi$ activation in obesity. IL-4/Irs2/Akt pathway was essential for

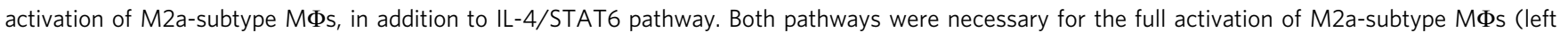
panel). In obesity, although IL-4/STAT6 pathway was maintained, IL-4/Irs2/Akt pathway was selectively impaired along with decreased Irs2 expression and stabilization of the FoxO1/HDAC3/NCoR1 corepressor complex in MФs (right panel)

in these mice, because PDK1 is a downstream molecule not only in the insulin signaling pathway, but also in the IL-4 signaling pathway. In fact, mice overexpressing CA-FoxO1 in the myeloid cells, which is thought to be associated with maintained Irs2 expression and decreased IL-4 signaling due to stabilization of FoxO1/HDAC3/NCoR1 corepressor complex in the MФs, showed reduced $M 2 a-s u b t y p e ~ M \Phi$ activation and increased inflammation and insulin resistance under the HF diet condition ${ }^{35}$. These data suggest that IR signaling contributes to IL-4 signaling via regulating Irs2 expression, mediating obesity-induced inflammation and insulin resistance under the HF diet condition.

Similar to the finding in the WAT, inflammation and insulin resistance were also noted in the livers of the MIrs2 $\mathrm{KO}$ mice. Increased inflammatory cytokine release from the adipose tissue may cause hepatic insulin resistance. In fact, hepatic insulin resistance was observed in mice showing overexpression of $M C P$ 1 in the adipose tissue, along with increased release of inflammatory cytokines such as TNF $\alpha$ and $I L-6^{33}$. +Kupffer cells, which are the resident $\mathrm{M} \Phi$ s in the liver, have been reported to contribute to hepatic inflammation and insulin resistance ${ }^{5,32}$. PPAR- $\delta$ deficiency has been shown to impair M2a-subtype MФ activation in Kupffer cells, thereby aggravating hepatic inflammation and insulin resistance in obesity ${ }^{11,12}$. In addition to Kupffer cells, M1-type MФs are recruited to the liver from the BM in obesity. The recruited hepatic MФs are similar to the M1type $M \Phi s$ in the adipose tissue ${ }^{36}$, and induce activation of proinflammatory pathways in the hepatocytes, thereby causing hepatic insulin resistance. Depletion of Kupffer cells and of the recruited hepatic $\mathrm{M} \Phi$ s using gadolinium or clodronate protected the mice from obesity-induced hepatic insulin resistance ${ }^{37,38}$. These data suggest three possibilities in respect of the mechanism underlying the hepatic inflammation and insulin resistance observed in MIrs2KO mice: increased inflammatory cytokine release from the adipose tissue, decreased M2a-subtype $\mathrm{M} \Phi$ activation caused by Irs 2 deficiency in the Kupffer cells, and/or newly recruited M1-type MФs in the liver.

Why was M2a-subtype $\mathrm{M} \Phi$ activation maintained under the NC diet condition in spite of the fact this activation decreased under the HF diet condition in the MIrs2KO mice (Fig. 2a and Supplementary Fig. 2g)? There are two possibilities: induction of compensatory pathways in an IL-13-dependent or IL-13independent manner. In type I receptor deficiency, M2asubtype $M \Phi$ activation was indeed shown to be induced by IL-
$13^{39}$. In type II receptor deficiency, on the other hand, IL-4 induced M2a-subtype MФ activation ${ }^{21}$, suggesting that both IL-4 and IL-13 activates M2a-subtype MФs vice versa. Mice with systemic STAT6 KO and myeloid-specific IL-4R $\alpha \mathrm{KO}$, which show defect in both IL-4 and IL-13 signaling, exhibited a significant reduction of M2a-subtype MФ activation in the ATMs under the NC diet condition ${ }^{16}$. In this study, although IL-4induced M2a-subtype activation was impaired in the BMDMs of the MIrs2KO mice, IL-13-induced M2a-subtype activation was maintained in these cells. Jmjd3-IRF4 pathways have also been reported to induce M2a-subtype $\mathrm{M} \Phi$ activation independently of the IL-13 signaling pathways ${ }^{40}$. These data suggest that the M2asubtype MФ activation observed in NC-fed MIrs $2 \mathrm{KO}$ mice may be compensated for in both an IL-13-dependent and IL-13independent manner.

In this study, we found that in obesity, the hyperinsulinemia presumably downregulates $M \Phi$ Irs2 expression, resulting in impaired IL-4-induced M2a-subtype $\mathrm{M} \Phi$ activation, and consequently, development of inflammation and insulin resistance in the liver and WAT.

\section{Methods}

Animals. To generate mice with targeted deletion of Irs2 in the myeloid lineage cells, mice with flanking loxP Irs 2 alleles $\left(\operatorname{Irs} 2^{\text {lox/lox }}\right)$ were crossed with LysozymeM-Cre transgenic mice ${ }^{41,42}$. Genotyping was performed by PCR amplification of the tail DNA from each mouse at 4 weeks of age, as previously reported $^{30}$. To generate mice with targeted deletion of the $I R$ in the myeloid lineage cells, we created $I R^{\text {lox/lox }}$ mice, carrying the IR allele with loxP sites flanking exon 4 (Supplementary Fig. 9a). The targeting construct to introduce loxP sites into the $I R$ gene was created from a $13-\mathrm{kb}$ clone of the IR gene containing exon 4 , as described previously, but with slight modification ${ }^{34}$. A targeting vector with the floxed neomycin-resistance gene was introduced into the $5^{\prime}$ side of the IR gene, and the loxP gene was introduced into the $3^{\prime}$ side (Supplementary Fig. 9a). The construct was transfected into J1 embryonic stem cells $(129 / \mathrm{Sv})$ by electroporation and screened for homologous recombinant clones by Southern blot analysis. The cells were injected into blastocysts from C57BL/6 mice and transferred into pseudopregnant ICR female mice to generate heterozygous mice, as previously reported ${ }^{41}$. To generate MIRKO mice, $I R^{\mathrm{lox} / \mathrm{lox}}$ mice were crossed with LysozymeM-Cre transgenic mice. The PCR primers used for the Cre recombinase were $5^{\prime}$ ACATGTTCAGGGATCGCCAGG-3' and 5' -TAACCAGTGAAACAGCATTGC$3^{\prime}$. To detect Cre-mediated recombination at the genomic DNA level in the BMDM by PCR, we designed primers for the upstream portion of the IR genomic DNA (primer a), Neo DNA (primer b), and the downstream portion of the IR genomic DNA (primer c). Primer a was 5'-TGCCTAGAGACTCCAAGACAAA-3', primer b was 5'-CAGCGCATCGCCTTCTATCGCCTTC-3' and primer c was 5'CTGCAAAAAGGAGGAAATGC-3', Primer pairs 'a' and 'b' or 'a' and 'c' yielded PCR products about $250 \mathrm{bp}$ and $627 \mathrm{bp}$ in length before and after Cre-mediated $I R$ 
deletion, respectively (Supplementary Fig. 9b). Although the original MIrs2KO and MIRKO mice were derived from a C57BL/6 and 129/Sv mixed background, these mice were backcrossed more than eight times with C57BL/6 mice. All experiments in this study were performed using male littermates, and $I r s 2^{\text {lox } / l o x}$ and $I R^{l o x} /$ lox mice were used as the controls. The mice were housed under a 12-h light/dark cycle at $22.5-23.5^{\circ} \mathrm{C}$ and given access to food ad libitum. Standard (CE-2) and HF (HF32) diets were also purchased from Japan CLEA. The composition of the HF diet was: $20 \%$ safflower oil, $15.8 \%$ beef tallow, $24.5 \%$ casein, $6.75 \%$ sucrose, $5.5 \%$ cellulose, $5.0 \%$ mineral mixture, and $1.4 \%$ vitamin mixture. The HF diet was administered to the mice for 17-20 weeks starting at 8 weeks of age. The animal care and experimental procedures used in this study were approved by the Animal Care Committee of the University of Tokyo.

Isolation of the peritoneal MФs and flow cytometry. Mice were injected intraperitoneally with $3 \%$ sodium thioglycollate (Wako). After four days, peritoneal MФs were collected and stimulated with IL-4. Epididymal adipose tissue specimens isolated from mice were rinsed in PBS, minced into fine pieces, and digested with Tyrode buffer ( $130 \mathrm{mM} \mathrm{NaCl}, 5.4 \mathrm{mM} \mathrm{KCl}, 0.5 \mathrm{mM} \mathrm{MgCl}, 0.33 \mathrm{mM} \mathrm{NaH} \mathrm{PO}_{4}$, $22 \mathrm{mM}$ glucose, $5 \mathrm{mM}$ L-glutamine, and $25 \mathrm{mM}$ HEPES) containing collagenase (Worthington) at $37^{\circ} \mathrm{C}$ using a water bath for $15 \mathrm{~min}$. Then, the samples were passed through a mesh and centrifuged in a swing rotor at $362 \times g$. The pellets were collected as the stromal-vascular fraction (SVF), and the SVF cells were incubated in $1 \times$ Pharm Lyse (BD Biosciences) for $8 \mathrm{~min}$ at room temperature. The cells were suspended in PBS containing 2\% BSA, and incubated with anti-CD16/32 (553142, $\mathrm{BD}$ pharmingen) for $5 \mathrm{~min}$ on ice. Then, the cells were incubated with the primary antibodies or the matching control isotypes for $1 \mathrm{~h}$ on ice, and analyzed using a FACS Aria II cell sorter (BD Biosciences) and FlowJo (Tree Star, Ashland, OR). SiglecF-negative/F4/80-positive/CD11b-positive cells were sorted and used for the RNA extraction. Furthermore, the cells were also divided CD11c-positive/CD206negative and CD11c-negative/CD206-positive cells, as M1-type and M2-type MФs, respectively.

Glucose and pyruvate tolerance test. Mice were loaded with oral glucose at 1.5 $\mathrm{mg} / \mathrm{g}$ body weight after being denied access to food for $24 \mathrm{~h}$. Blood samples were taken at different time-points and the blood concentrations of glucose were measured with an automatic glucometer (Glutest Ace, Sanwa Chemical Co., Nagoya, Japan). Blood samples were collected and centrifuged in heparinized tubes, and the separated plasma samples were stored at $-20^{\circ} \mathrm{C}$. Insulin levels were determined using a mouse insulin ELISA kit (Morinaga). Pyruvate tolerance test were performed after the animals were denied access to food for $16 \mathrm{~h}$. The mice were injected intraperitoneally with pyruvate dissolved in saline $(1.5 \mathrm{~g} / \mathrm{kg})$, and blood samples were obtained from the tail vein at different time-points.

Hyperinsulinemic-euglycemic clamp. An infusion catheter was inserted into the right jugular vein of the mice, as described previously ${ }^{30}$. To measure the GIR, a primed-continuous infusion of insulin (Humulin R; Lilly) was administered at the dose of 7.5 milliunits $/ \mathrm{kg} / \mathrm{min}$ to the HF-diet-fed mice, and the blood glucose concentration, monitored every $5 \mathrm{~min}$, was maintained at approximately $120 \mathrm{mg} / \mathrm{dl}$ by the administration of glucose ( $5 \mathrm{~g}$ of glucose $/ 10 \mathrm{ml}$ enriched to about $20 \%$ with $\left[6,6-{ }^{2} \mathrm{H}_{2}\right]$ glucose (Sigma)) for $120 \mathrm{~min}$. Blood samples $(20 \mu \mathrm{l})$ were obtained for 15 or $30 \mathrm{~min}$ before the end of the hyperinsulinemic-euglycemic clamp. Thereafter, the Rd was calculated according to nonsteady-state equations, and the EGP was calculated as the difference between the Rd value and the exogenous GIR.

Insulin signaling in the liver, eWAT and skeletal muscle. To investigate the insulin signaling in the liver, eWAT and skeletal muscle, insulin $(6 \mathrm{ng} / \mathrm{ml})$ (Humulin R; Lilly) was injected via the inferior vena cava. The liver, eWAT and skeletal muscle were dissected $10 \mathrm{~min}$ after the insulin infusion and immediately frozen in liquid nitrogen. The samples were then analyzed by western blot analysis.

Hepatic TG content. For determining the hepatic TG content, each liver sample was homogenized in buffer A $(25 \mathrm{mM}$ Tris- $\mathrm{HCl}, \mathrm{pH} 7.4,10 \mathrm{mM}$ sodium orthovanadate, $10 \mathrm{mM}$ sodium pyrophosphate, $100 \mathrm{mM}$ sodium fluoride, $10 \mathrm{mM}$ EDTA, $10 \mathrm{mM}$ EGTA and $1 \mathrm{mM}$ phenylmethylsulfonyl fluoride), as previously reported ${ }^{31}$. 2:1 (vol/vol) chloroform/methanol was added to the homogenate and the mixture was shaken for $15 \mathrm{~min}$. After centrifugation at $17,753 \times \mathrm{g}$ for $10 \mathrm{~min}$, the organic layer was collected. This extraction was repeated three times, and the collected samples were dried and resuspended in 1\% Triton X-100/ethanol. The TG content in the extracted sample was measured using Triglyceride E-test Wako (Wako Pure Chemical Industries Ltd., Osaka, Japan).

Immunohistochemistry. eWAT specimens were fixed with $10 \%$ formalin and embedded in paraffin. Quantification of the adipocyte size and F4/80-positive area were carried out using the image analyzer software, Win ROOF (Mitani Corp), as previously reported ${ }^{41}$. The BMDM were also fixed in $4 \%$ paraformaldehyde in PBS for $30 \mathrm{~min}$ on ice and blocked using 3\% bovine serum albumin (BSA)/PBS for at least $1 \mathrm{~h}$ at room temperature. FoxO1 (2880, Cell signaling, 1:100) antibody was added, followed by incubation in blocking buffer (3\% BSA/PBS) overnight at $4{ }^{\circ} \mathrm{C}$.
The antibody reactivity was detected using Alexa Fluor 488-conjugated anti-rabbit IgG, a diaminobenzidine (DAB) substrate (Pierce). Fluorescence images were acquired using an Olympus IX71 microscope.

Bone marrow-derived MФs. Bone marrow cells were isolated from the femur, tibia and humerus bones of the mice, as previously reported ${ }^{30}$. The cells, suspended in RPMI-1640 medium (supplemented with 15\% FCS, 1\% penicillin-streptomycin) were plated. The floating cells were collected after incubation for $16 \mathrm{~h}$ and plated at a concentration of $1 \times 10^{6}$ cells $/ \mathrm{ml}$ in RPMI-1640 medium (supplemented with $15 \%$ FCS, $1 \%$ penicillin-streptomycin and $50 \mathrm{ng} / \mathrm{ml}$ recombinant M-CSF (Shenandoah biotechnology)) in 10-cm Petri dishes and allowed to differentiate for 8-10 days. For M1-type $М \Phi$ activation, the BMDM were treated with $5 \mathrm{ng} / \mathrm{ml}$ of LPS (Sigma), while for M2a-subtype MФ activation, the cells were treated with 10 $\mathrm{ng} / \mathrm{ml}$ of IL-4 (Peprotech) or $20 \mathrm{ng} / \mathrm{ml}$ of IL-13 (Peprotech). The cells were exposed to a PI3 kinase inhibitor (10 $\mu \mathrm{M}$ LY294002) $30 \mathrm{~min}$ before the addition of IL-4.

Immunoprecipitation and western blot analysis. To prepare the lysates, the cells and tissues were homogenized in buffer A $(25 \mathrm{mM}$ Tris- $\mathrm{HCl}, \mathrm{pH} 7.4,10 \mathrm{mM}$ sodium orthovanadate, $10 \mathrm{mM}$ sodium pyrophosphate, $100 \mathrm{mM}$ sodium fluoride, $10 \mathrm{mM}$ EDTA, $10 \mathrm{mM}$ EGTA and $1 \mathrm{mM}$ phenylmethylsulfonyl fluoride). For immunoprecipitation of Ir $\beta$, Irs1 and Irs2, the lysates were incubated with rabbit polyclonal antibody against Ir $\beta$ (sc-711, Santa Cruz), Irs1 (06-248, Millipore) or Irs2 (3089, Cell Signaling) for $1 \mathrm{~h}$ at $4^{\circ} \mathrm{C}$. Then, protein G-Sepharose was added, followed by incubation for a further $1 \mathrm{~h}$ at $4{ }^{\circ} \mathrm{C}$. Thereafter, after washing 3 times with buffer $\mathrm{A}$, the immunocomplexes were resolved on $7 \%$ or $10 \%$ SDS-PAGE. Phosphorylated or total protein was analyzed by immunoblotting using specific antibodies against Ir $\beta$, Irs1, Irs2 and phosphotyrosine. Phosphorylated or total protein of Akt, FoxOl and STAT6 was isolated by immunoblotting using specific antibodies after the tissue lysates were resolved by SDS-PAGE and transferred to a Hybond-P PVDF transfer membrane (Amersham Biosciences). Bound antibodies were detected with HRP-conjugated secondary antibodies using ECL detection reagents (Amersham Biosciences). Uncropped scans of the blots can be found as a Supplementary Figure in the Supplementary Information (Supplementary Fig. 10 and Supplementary Fig. 11).

RNA extraction and real-time PCR. RNA was isolated from the cells and tissues with the Qiagen RNeasy Kit (Qiagen, Germany), in accordance with the manufacturer's instructions. One microgram of RNA was used for generating cDNA using random hexamers with MultiScribe reverse transcription reagents (ABI). TaqMan quantitative PCR (cycles of $50^{\circ} \mathrm{C}$ for $2 \mathrm{~min}, 95^{\circ} \mathrm{C}$ for $10 \mathrm{~min}$, followed by 40 cycles of $95^{\circ} \mathrm{C}$ for $15 \mathrm{~s}, 60^{\circ} \mathrm{C}$ for $1 \mathrm{~min}$ ) was then performed with ABI Prism 7900 PCR (Applied Biosystems) to amplify IR (Mm 00439693_m1), Irs 1 (Mm00439720_s1), Irs2 (Mm03038438_m1), IL-4R (Mm00439634_m1), STAT6 (Mm01160477_m1), Arg1 (Mm00475988_m1), FIZZ1 (Mm00445109_m1), Ym1 (Mm00657889_mH), Mgl1 (Mm0054612_m1), IL-10 (Mm00439614_m1), TNF (Mm 00443258_m1), MCP-1(Mm00441242_m1), IL-6 (Mm00446190_m1), CCR2 (Mm99999051_gH), IL-1 (Mm00434228_m1), IL-18 (Mm00434225_m1), PEPCK (Mm00440636_m1), G6Pase (Mm 00839363_m1), ACC (Mm01304287_m1), FAS (Mm01253300_g1), SCD1 (Mm00772290_m1), PPARy (Mm00440945_m1), FSP27 (Mm00617672_m1), CD36 (Mm 00432403_ml), PGC1 $\beta$ (Mm01258518_m1), PPAR (Mm01305434_m1), IL-12a (Mm00434169_m1), IL-12b

(Mm01288989_m1), and $\beta$-actin (Mm00607939_s1) cDNA from the samples. The primers for the other reactions were purchased from Applied Biosystems. The expression level of each of the transcripts was normalized to the constitutive expression level of $\beta$-actin mRNA.

Arginase assays. After the BMDM $\left(5.0 \times 10^{6}\right.$ cells $)$ were stimulated with IL- 4 for $48 \mathrm{~h}$, the cells were collected in ice-cold PBS. The cells were then lysed in buffer containing $0.4 \%$ Triton-X-100 and protease inhibitors, and the arginase activity were measured using the Arginase Assay Kit (Abnova), according to the manufacturer's instructions. The lysed cells were centrifuged at $14,000 \times g$ at $4{ }^{\circ} \mathrm{C}$ for 10 $\mathrm{min}$, and the supernatants were plated on to a 96 -well microtiter plate. L-arginine was converted to urea by a buffer containing a substrate and cofactor, and the absorbance of the samples was measured using a microplate reader at the wavelength of $430 \mathrm{~nm}$.

siRNA transfections and adenovirus-mediated gene transfer. The BMDM were transfected with adenovirus containing murine cDNA encoding FoxO1-T24A/ S253D/S316 $\mathrm{A}^{43}$. Five days later, the cells were treated with IL-4 and the harvested samples were then used for the gene expression analyses. The Neon ${ }^{\circledR}$ Transfection System (Invitrogen) was used for the siRNA transfection. The BMDM were suspended at the density of $1.2 \times 10^{7} \mathrm{cells} / \mathrm{ml}$ in resuspension buffer $\mathrm{T}$ (Invitrogen), and incubated with $200 \mathrm{mM}$ of siRNA (siFoxO1, 7892394, Invitrogen; siHDAC3, s67421, Ambion; siNCoR1, s73229, Ambion; siSTAT6, sc-36570, Sant Cruz; siCont 4390843, Ambion). The pulse conditions were as follows: square wave, $1600 \mathrm{~V}, 1$ pulse, $20 \mathrm{~ms}$ pulse length. The RNAi efficiency was confirmed by quantitative realtime PCR and the silenced BMDM were used for the functional assays $72-96 \mathrm{~h}$ after the electroporation. BMDM transfected with siRNA were stimulated with 10 $\mathrm{ng} / \mathrm{ml} \mathrm{IL}-4$ for $20 \mathrm{~h}$ after pretreatment with $100 \mathrm{nM}$ of insulin for $8 \mathrm{~h}$. 
Dual luciferase assays. Several DNA fragments containing the mouse Arg1, FIZZ1 and $Y m 1$ promoters were PCR-amplified from mouse genomic DNA. The PCR products were ligated using the pGEM-T Easy vector (Promega) and their nucleotide sequences were verified by DNA sequencing. Mutation of the Arg1 promoter was produced using the PrimerSTAR mutagenesis basal kit (Takara). These promoter fragments were cloned into the luciferase reporter pGL3-Basic vector (Promega, Madison, WI). Transfection was carried out at 70-80\% confluence of the RAW264.7 cells (Cat. No. EC91062702, DS Pharma Biomedical) using $2.25 \mu \mathrm{g}$ of the Arg1-, FIZZ1-, or Ym1-luciferase reporter gene (pGL3); $0.5 \mu \mathrm{g}$ of the Renilla luciferase reporter vector (phRL-SV40; Promega) was used as the internal control for determining the transfection efficiency. After the cells were transfected using the Neon transfection system (Invitrogen), the transfected cells were treated with $10 \mathrm{ng} / \mathrm{ml}$ of IL-4 for $24 \mathrm{~h}$. The luciferase activities were measured using the Dual-Glo Luciferase Assay System (Promega), according to the manufacturer's protocol.

EMSA. Nuclear protein extracts were prepared from RAW 267.4 cells before IL-4 treatment. A double-stranded oligonucleotide containing the consensus forkhead binding region in the Argl promoter area was labeled using the Biotin 3' End DNA Labeling Kit (PIERCE). This biotin-labeled oligonucleotide probe $(20 \mathrm{fmol})$ was incubated with the nuclear extracts in the presence of $10 \mathrm{mM}$ Tris- $\mathrm{HCl}(\mathrm{pH} 7.5)$, $50 \mathrm{mM} \mathrm{NaCl}, 1 \mathrm{mM} \mathrm{MgCl} 2,0.5 \mathrm{mM}$ EDTA, $4 \%$ glycerol and $0.5 \mathrm{mM}$ DTT for 20 min at room temperature using the LightShift ${ }^{\circledast}$ Chemiluminescent EMSA Kit (Thermo scientific). For the competition experiments, the nuclear extracts were incubated with $0,1,2$ or $5 \mu \mathrm{l}$ of anti-FoxO1 (2880, Cell Signaling), anti-HDAC3 ((3949, Cell Signaling) or anti-NCoR1 (5948, Cell Signaling)) antibody, or an equal amount of normal rabbit or IgG (sc-2027, Santa Cruz) for $60 \mathrm{~min}$ at room temperature. The non-denaturing binding reaction mixture was applied for electrophoresis on $6 \%$ polyacrylamide gels. The nylon membrane transferred from the gels was crosslinked using a commercial UV-light crosslinking instrument equipped with $254 \mathrm{~nm}$ bulbs and visualized by chemiluminescence.

Co-culture system. 3T3-L1 preadipocytes (ECACC 86052701) were purchased from DS Pharma Biomedical Co., Ltd. Co-culture was performed using the Transwell system (Merck Millipore) with a $0.4 \mu \mathrm{m}$ porous membrane to separate the upper chambers from the lower ones, as previously described, with some modifications ${ }^{12}$. In the lower chambers, 3T3-L1 preadipocytes were seeded into 12well plates at $0.8 \times 10^{4}$ cells per well and cultured to confluence in 3T3-L1 preadipocyte medium (DS Pharma Biomedical Co., Ltd). At 2 days post confluence, the cells were induced to differentiate using the 3T3-L1 differentiation medium (DS Pharma Biomedical Co., Ltd), and then used after 8 days. The BMDM of the control, MIrs2KO or C57BL/6 mice were plated at a concentration of $1 \times 10^{6}$ cells/ $\mathrm{ml}$ in $10 \mathrm{~cm}$ Petri dishes containing RPMI-1640 medium and allowed to differentiate for 8 days. The BMDM $\left(0.8 \times 10^{6}\right.$ cells per well $)$ were plated into the upper chambers. Twenty-four hours after the plating, FCS and M-CFS-free RPMI 1640 medium plus $100 \mathrm{nM}$ insulin were added to the BMDM and 3T3-L1 adipocyte cultures. After further incubation for $24 \mathrm{~h}$, the conditioned medium, 3T3-L1 cells and BMDM were collected and analyzed. The measurements of IL-4 (Abcam) and IL-13 (Cusabio) were conducted using mouse ELISA kits.

ChIP assay. BMDM $\left(0.8 \times 10^{6}\right.$ cells $)$ were plated in $10-\mathrm{cm}$ dishes and stimulated or not stimulated with $10 \mathrm{ng} / \mathrm{ml}$ of IL-4. The cells were fixed with $37 \%$ paraformaldehyde for $10 \mathrm{~min}$ at room temperature, and quenched with glycine for $5 \mathrm{~min}$ at room temperature. The collected cells were lysed using a buffer containing protease inhibitor from a shearing ChIP kit (Diagenode). The cells were sonicated for 18 cycles ( $30 \mathrm{~s}$ "ON", $30 \mathrm{~s}$ "OFF") at $200 \mathrm{~W}$ on ice using an ultrasonic homogenizer (Bioruptor UCW-310, Cosmo Bio Co.) to shear chromatin. Samples were diluted to $1.8 \mathrm{ml}$ with the ChIP Dilution Buffer (50 mM Tris-HCL pH 8, $167 \mathrm{mM}$ $\mathrm{NaCl}, 1.1 \%$ Triton X-100, $0.11 \%$ sodium deoxycholate, protease inhibitor cocktail) and precleared for $2 \mathrm{~h}$ at $4{ }^{\circ} \mathrm{C}$ with $50 \%$ protein G sepharose/salmon sperm DNA. After removal of the sepharose beads by centrifugation, immunoprecipitation was performed with ChIP-graded anti-FoxO1 (sc-11350, Santa Cruz, 1:50) HDAC3 (sc11417, Santa Cruz, 1:50) and NCoR1 (sc-1609, Santa Cruz, 1:50) antibodies or an equal amount of normal rabbit (sc-2027, Santa Cruz, 1:50) or goat IgG (sc-2028, Santa Cruz, 1:50), followed by incubation overnight at $4{ }^{\circ} \mathrm{C}$; then, precipitation of the antibody-protein-DNA complexes with $50 \%$ protein $\mathrm{G}$ sepharose/salmon sperm DNA was performed for $2 \mathrm{~h}$ at $4{ }^{\circ} \mathrm{C}$. The precipitates were sequentially washed with buffers containing $0.1 \%$ SDS, $1 \%$ Triton X-100, 2 mM EDTA, and 20 $\mathrm{mM}$ Tris- $\mathrm{HCl}$ ( $\mathrm{pH} 8.1$ ) supplemented with either $150 \mathrm{mM}$ (buffer I) or $500 \mathrm{mM}$ $\mathrm{NaCl}$ (buffer II), prior to a final wash in $250 \mathrm{mM} \mathrm{LiCl}, 1 \% \mathrm{NP}-40,1 \%$ deoxycholate, $1 \mathrm{mM}$ EDTA and $10 \mathrm{mM}$ Tris- $\mathrm{HCl}$ (pH 8.1). The pellets were washed with TrisEDTA buffer and extracted with $1 \%$ SDS, $10 \mathrm{mM}$ EDTA and $50 \mathrm{mM}$ Tris- $\mathrm{HCl}(\mathrm{pH}$ 8.0). After heating at $65^{\circ} \mathrm{C}$ overnight, the proteins were digested with proteinase $\mathrm{K}$, and the DNA was purified. The samples were subjected to PCR using the following primers: for Arg1: 5'-GAATAGCACTTGGCACACGA-3' and 5'-ACACTGTCTAGGAAAGCATG-3'.

Co-immunoprecipitation assay. Stimulated BMDM were washed in ice-cold PBS, and harvested by scraping. The cells were centrifuged at $815 \times g$ for $4 \mathrm{~min}$ at $4{ }^{\circ} \mathrm{C}$, followed by addition of a co-immunoprecipitation (CO-IP) buffer (50 mM HEPES,
pH 8.0, $50 \mathrm{mM} \mathrm{NaF}, 10 \mathrm{mM} \mathrm{Na} 4 \mathrm{P} 2 \mathrm{O} 7,50 \mathrm{mM} \mathrm{NaCl}, 5 \mathrm{mM}$ EDTA, $1 \mathrm{mM}$ $\mathrm{Na}_{3} \mathrm{VO}_{4}, 0.25 \%$ sodium deoxycholate, $1 \% \mathrm{NP}-40$ with a protease inhibitor cocktail (Roche)). The cells were suspended and placed on ice for $30 \mathrm{~min}$. The samples were then centrifuged at $20,379 \times g$ for $5 \mathrm{~min}$ at $4{ }^{\circ} \mathrm{C}$, and the supernatants were saved as the cell lysates. The prepared cell lysates were incubated with each antibody for $3 \mathrm{~h}$ at $4{ }^{\circ} \mathrm{C}$, followed by addition of protein G-sepharose beads (GE healthcare). After additional incubation for $1 \mathrm{~h}$ at $4^{\circ} \mathrm{C}$, the beads were washed three times with $\mathrm{CO}$ IP buffer containing a protease inhibitor cocktail and resuspended in Laemmli buffer. The coimmunoprecipitated proteins were resolved by SDS-polyacrylamide gel electrophoresis (PAGE), and identified by western blot analysis. Uncropped scans of the blots can be found as a Supplementary Figure in the Supplementary Information (Supplementary Fig. 10).

Antibodies. For the western blot analysis, rabbit polyclonal antibody directed against Ir $\beta$ (sc-711, Santa Cruz, 1:2000) and $\beta$-actin (A5441, SIGMA, 1:5000) was purchased from Santa Cruz Biotechnology. Rabbit polyclonal antibodies directed against Irs1 (06-248, Millipore, 1:2000) and Irs2 (MABS15, Millipore, 1:2000) and a mouse monoclonal antibody directed against phosphotyrosine (05-321, Millipore, 1:5000) were purchased from Millipore. Rabbit polyclonal antibodies directed against Akt (9272, Cell Signaling, 1:5000), phospho-Akt (Ser-473) (9271, Cell Signaling, 1:2000), phospho-FoxO1 (Ser-256) (9461, Cell Signaling, 1:1000), STAT6 (9362, Cell Signaling, 1:1000), FoxO1 (2880, Cell Signaling, 1:1000), Lamin B1 (9087, Cell Signaling, 1:2000) and G3PDH (2118, Cell Signaling, 1:2000) were purchased from Cell Signaling Technology. The rabbit polyclonal antibody directed against phospho-STAT6 (Tyr641) (06-937, Millipore, 1:1000) was purchased from Millipore. The antibodies used for the flow cytometry were SiglecF-PE (552126, BD Biosciences), CD11b-APC-Cy7 (557657, BD Biosciences), F4/80-FITC (11-4801, eBioscience), CD11c-eFluor405 (48-0114, eBioscience), and CD206-APC (141708, Biolegend). For the co-immunoprecipitation and EMSA, antibodies against HDAC3 (3949, Cell Signaling, 1:1000) and NCoR1 (5948, Cell Signaling, 1:1000) were used.

Transwell migration assay. Chemotaxis of BMDM was quantified using the Cultrex 24 well cell migration assay kit (Trevigen). The BMDM $\left(0.5 \times 10^{6} / \mathrm{ml}\right)$ were placed in the top chamber and $100 \mathrm{ng} / \mathrm{ml}$ of recombinant MCP-1 (R \& D systems) was added at $0.5 \% \mathrm{FBS} / \mathrm{RPMI}$ to the bottom chamber. After incubation for $4 \mathrm{~h}$ at $37^{\circ} \mathrm{C}$, the cells in the bottom chamber were collected by cell dissociation. The collected cells were read at $520 \mathrm{~nm}$ emission and $485 \mathrm{~nm}$ excitation.

Proliferation assay. BMDM $\left(0.2 \times 10^{5}\right)$ were seeded in 96 -well plates in volumes of $100 \mu \mathrm{l} /$ well. After the cells were stimulated with $10 \mathrm{ng} / \mathrm{ml}$ of IL-4 for $24 \mathrm{~h}$, BrdU was added at a final concentration of $1 \mu \mathrm{M}$. DNA synthesis was assayed by the Cell Proliferation ELISA, BrdU (Roche Molecular Biochemicals), using a luminometer (Promega).

STZ plus phlorizin. STZ (Sigma) was freshly suspended in sodium citrate buffer (pH 4.5). The suspension was injected intraperitoneally $(150 \mathrm{mg} / \mathrm{kg}$ ) on day 0 and day 5 to 8 -week-old C57BL/6 mice that had been denied access to food for $5 \mathrm{~h}$. Phlorizin (Wako) was dissolved in a solution containing 10\% ethanol, 15\% DMSO and $75 \%$ saline, and injected subcutaneously $(0.4 \mathrm{~g} / \mathrm{kg})$ twice daily for 7 days starting from day 7 after the STZ injection. Peritoneal MФs were then collected after injection of thioglycolate solution (Wako).

Blood sample assay. Plasma levels of TG, FFA, T-ch and HDL (Wako Pure Chemical Industries, Ltd) were assayed by enzymatic methods.

Statistical Analysis. Values are expressed as the mean \pm SEM and were analyzed using the JMP 11 software (SAS Institute). Student's $t$ test was used to analyze the statistical significances of differences between two groups, and ANOVA to analyze the statistical significances of differences among multiple groups. The TukeyKramer test was used for post hoc analysis. The statistical significance level was set at $P \leq 0.05$ in all the tests.

\section{Data availability}

The authors declare that all data supporting the findings of this study are available within the manuscript and its Supplementary Information files or are available from the author upon reasonable request.

Received: 17 November 2017 Accepted: 22 October 2018 Published online: 19 November 2018

\section{References}

1. Olefsky, J. M. \& Glass, C. K. Macrophages, inflammation, and insulin resistance. Annu. Rev. Physiol. 72, 219-246 (2010). 
2. Gregor, M. F. \& Hotamisligil, G. S. Inflammatory mechanisms in obesity. Annu. Rev. Immunol. 29, 415-445 (2011).

3. Weisberg, S. P. et al. Obesity is associated with macrophage accumulation in adipose tissue. J. Clin. Invest. 112, 1796-1808 (2003).

4. Arkan, M. C. et al. IKK-beta links inflammation to obesity-induced insulin resistance. Nat. Med. 11, 191-198 (2005).

5. Cai, D. et al. Local and systemic insulin resistance resulting from hepatic activation of IKK- $\beta$ and NF-kB. Nat. Med. 11, 183-190 (2005).

6. Kanda, H. et al. MCP-1 contributes to macrophage infiltration into adipose tissue, insulin resistance, and hepatic steatosis in obesity. J. Clin. Invest. 116, 1494-1505 (2006).

7. Weisberg, S. P. et al. CCR2 modulates inflammatory and metabolic effects of high-fat feeding. J. Clin. Invest. 116, 115-124 (2006).

8. Patsouris, D. et al. Ablation of CD11c-positive cells normalizes insulin sensitivity in obese insulin resistant animals. Cell. Metab. 8, 301-309 (2008).

9. Gordon, S. \& Taylor, P. R. Monocyte and macrophage heterogeneity. Nat. Rev. Immunol. 5, 953-964 (2005).

10. Lumeng, C. N., DelProposto, J. B., Westcott, D. J. \& Saltiel, A. R. Phenotypic switching of adipose tissue macrophages with obesity is generated by spatiotemporal differences in macrophage subtypes. Diabetes 57, 3239-3246 (2008).

11. Odegaard, J. I. et al. Alternative M2 activation of Kupffer cells by PPAR $\delta$ ameliorates obesity-induced insulin resistance. Cell. Metab. 7, 496-507 (2008).

12. Kang, K. et al. Adipocyte-derived Th2 cytokines and myeloid PPAR $\delta$ regulate macrophage polarization and insulin sensitivity. Cell Metab. 7, 485-495 (2008).

13. Mantovani, A. et al. The chemokine system in diverse forms of macrophage activation and polarization. Trends Immunol. 25, 677-686 (2004).

14. Hristodorov, D., Mladenov, R., Huhn, M., Barth, S. \& Thepen, T. Macrophage-targeted therapy: CD64-based immunotoxins for treatment of chronic inflammatory diseases. Toxins 4, 676-694 (2012).

15. Wu, D. et al. Eosinophils sustain adipose alternatively activated macrophages associated with glucose homeostasis. Science 332, 243-247 (2011).

16. Odegaard, J. I. et al. Macrophage-specific PPAR $\gamma$ controls alternative activation and improves insulin resistance. Nature 447, 1116-1120 (2007).

17. Nelms, K., Keegan, A. D., Zamorano, J., Ryan, J. J. \& Paul, W. E. The IL-4 receptor: signaling mechanisms and biologic functions. Annu. Rev. Immunol. 17, 701-738 (1999).

18. Hershey, G. K. IL-13 receptors and signaling pathways: an evolving web. J. Allergy Clin. Immunol. 111, 677-690 (2003). quiz 691.

19. Qiu, Y. et al. Eosinophils and type 2 cytokine signaling in macrophages orchestrate development of functional beige fat. Cell 157, 1292-1308 (2014).

20. Wang, L. M., Keegan, A., Frankel, M., Paul, W. E. \& Pierce, J. H. Signal transduction through the IL-4 and insulin receptor families. Stem Cells 13, 360-368 (1995).

21. Heller, N. M. et al. Type I IL-4Rs selectively activate IRS-2 to induce target gene expression in macrophages. Sci. Signal. 1, ra17 (2008).

22. Welham, M. J. et al. Insulin Receptor Substrate-2 is the major $170-\mathrm{kDa}$ protein phosphorylated on tyrosine in response to cytokines in murine lymphohemopoietic cells. J. Biol. Chem. 272, 1377-1381 (1997).

23. Fujisaka, S. et al. Regulatory mechanisms for adipose tissue M1 and M2 macrophages in diet-induced obese mice. Diabetes 58, 2574-2582 (2009).

24. Jenkins, S. J. et al. IL-4 directly signals tissue-resident macrophages to proliferate beyond homeostatic levels controlled by CSF-1. J. Exp. Med. 210, 2477-2491 (2013).

25. Pauleau, A. L. et al. Enhancer-mediated control of macrophage-specific arginase I expression. J. Immunol. 172, 7565-7573 (2004).

26. Kitamura, T. et al. Forkhead protein FoxO1 mediates Agrp-dependent effects of leptin on food intake. Nat. Med. 12, 534-540 (2006).

27. Zhang, J. et al. Insulin inhibits transcription of IRS-2 gene in rat liver through an insulin response element (IRE) that resembles IREs of other insulinrepressed genes. Proc. Natl Acad. Sci. USA 98, 3756-3761 (2001).

28. Hirashima, Y. et al. Insulin down-regulates insulin receptor substrate-2 expression through the phosphatidylinositol 3-kinase/Akt pathway. J. Endocrinol. 179, 253-266 (2003).

29. Kubota, N. et al. Dynamic functional relay between insulin receptor substrate 1 and 2 in hepatic insulin signaling during fasting and feeding. Cell Metab. 8, 49-64 (2008).

30. Kubota, T. et al. Impaired insulin signaling in endothelial cells reduces insulininduced glucose uptake by skeletal muscle. Cell Metab. 13, 294-307 (2011).

31. Bluher, M. et al. Adipose tissue selective insulin receptor knockout protects against obesity and obesity-related glucose intolerance. Dev. Cell 3, 25-38 (2002).

32. Osborn, O. \& Olefsky, J. M. The cellular and signaling networks linking the immune system and metabolism in disease. Nat. Med. 18, 363-374 (2012).

33. Kamei, N. et al. Overexpression of monocyte chemoattractant protein-1 in adipose tissues causes macrophage recruitment and insulin resistance. J. Biol. Chem. 281, 26602-26614 (2006).
34. Mauer, J. et al. Myeloid cell-restricted insulin receptor deficiency protects against obesity-induced inflammation and systemic insulin resistance. PLoS Genet. 6, e1000938 (2010).

35. Kawano, Y. et al. Loss of Pdk1-Foxol signaling in myeloid cells predisposes to adipose tissue inflammation and insulin resistance. Diabetes 61, 1935-1948 (2012).

36. Obstfeld, A. E. et al. C-C chemokine receptor 2 (CCR2) regulates the hepatic recruitment of myeloid cells that promote obesity-induced hepatic steatosis. Diabetes 59, 916-925 (2010).

37. Neyrinck, A. M. et al. Critical role of Kupffer cells in the management of dietinduced diabetes and obesity. Biochem. Biophys. Res. Commun. 385, 351-356 (2009).

38. Lanthier, N. et al. Kupffer cell activation is a causal factor for hepatic insulin resistance. Am. J. Physiol. Gastrointest. Liver Physiol. 298, G107-G116 (2010).

39. Sheikh, F. et al. The interleukin-13 receptor- $\alpha 1$ chain is essential for induction of the alternative macrophage activation pathway by IL-13 but not IL-4. J. Innate Immun. 7, 494-505 (2015).

40. Satoh, T. et al. The Jmjd3-Irf4 axis regulates M2 macrophage polarization and host responses against helminth infection. Nat. Immunol. 11, 936-944 (2010).

41. Kubota, N. et al. Insulin receptor substrate 2 plays a crucial role in $\beta$ cells and the hypothalamus. J. Clin. Invest. 114, 917-927 (2004).

42. Clausen, B. E., Burkhardt, C., Reith, W., Renkawitz, R. \& Forster, I. Conditional gene targeting in macrophages and granulocytes using LysMcre mice. Transgenic. Res. 8, 265-277 (1999).

43. Nakae, J., Park, B. C. \& Accili, D. Insulin stimulates phosphorylation of the forkhead transcription factor FKHR on serine 253 through a Wortmanninsensitive pathway. J. Biol. Chem. 274, 15982-15985 (1999).

\section{Acknowledgements}

We thank Ayami Gouda, Yurika Shiraishi, Masatsugu Takayasu, Manami Takagi, Tamao Iwakami, Shiho Nemoto, Namiko Kasuga, Tomoko Asano, Eriko Nozaki and Kousuke Yokota for their excellent technical assistance and assistance with the animal care. This work was supported by a grant for TSBMI from the Ministry of Education, Culture, Sports, Science and Technology of Japan, a Grant-in-Aid for Scientific Research (A) (16209030), (A) (18209033), and (S) (20229008) from the Ministry of Education, Culture, Sports, Science, and Technology of Japan (to T. Kadowaki), a Grant-in-Aid for Scientific Research (C) (19591037) and (B) (21390279) from the Ministry of Education, Culture, Sports, Science, and Technology of Japan (to N.K.).

\section{Author contributions}

T.Kubota, N.K. and T.Kadowaki. designed this study and wrote the manuscript. T. Kubota, M.I., I.T., T.M., K.I. and K.T. M.M. conducted the experimental research and analyzed the data. M.M.,T.Y. and K.U. contributed to the data discussion. T.Kadowaki is the guarantor for this work, and as such, had full access to all the data in the study and takes responsibility for the integrity of the data and accuracy of the data analysis. All the authors gave their final approval for the manuscript version submitted for publication.

\section{Additional information}

Supplementary Information accompanies this paper at https://doi.org/10.1038/s41467018-07358-9.

Competing interests: The authors declare no competing interests.

Reprints and permission information is available online at http://npg.nature.com/ reprintsandpermissions/

Publisher's note: Springer Nature remains neutral with regard to jurisdictional claims in published maps and institutional affiliations.

Open Access This article is licensed under a Creative Commons Attribution 4.0 International License, which permits use, sharing, adaptation, distribution and reproduction in any medium or format, as long as you give appropriate credit to the original author(s) and the source, provide a link to the Creative Commons license, and indicate if changes were made. The images or other third party material in this article are included in the article's Creative Commons license, unless indicated otherwise in a credit line to the material. If material is not included in the article's Creative Commons license and your intended use is not permitted by statutory regulation or exceeds the permitted use, you will need to obtain permission directly from the copyright holder. To view a copy of this license, visit http://creativecommons.org/ licenses/by/4.0/

(c) The Author(s) 2018 